\title{
Is a shutdown of the thermohaline circulation irreversible?
}

\author{
Jianjun Yin, ${ }^{1,2}$ Michael E. Schlesinger, ${ }^{1}$ Natasha G. Andronova, ${ }^{3}$ Sergey Malyshev, ${ }^{4}$ \\ and $\mathrm{Bin} \mathrm{Li}^{1}$ \\ Received 4 August 2005; revised 13 December 2005; accepted 3 March 2006; published 22 June 2006.
}

[1] The Atlantic thermohaline circulation (THC) plays a vital role in explaining past abrupt climate changes and in maintaining the current climate. Its remarkable nonlinear dynamics, first demonstrated by H. M. Stommel, have been supported by various types of climate models. This has led to severe concerns that global warming may shut down the THC irreversibly, with consequent catastrophic climate changes, particularly for Europe. Here we use an uncoupled ocean general circulation model (OGCM) and a coupled atmosphere-ocean general circulation model (AOGCM) to investigate the nonlinear response of the THC to freshwater perturbations in the northern North Atlantic. We find that the THC shuts down irreversibly in the uncoupled OGCM simulations but reversibly in the coupled AOGCM simulations. This occurs because of different feedback processes operating in the uncoupled OGCM and AOGCM. The reversal of the THC in the uncoupled OGCM tends to stabilize the "off" mode of the THC by decreasing the mean salinity of the Atlantic, whereas a crucial negative feedback in the AOGCM helps the THC recover. This negative feedback results from complex air-sea interactions, and its operation needs the full participation of the atmosphere. Thus given the more realistic simulation by the AOGCM, the irreversible shutdown of the THC caused by freshwater addition appears to be an artifact of the uncoupled OGCM rather than a likely outcome of global warming.

Citation: Yin, J., M. E. Schlesinger, N. G. Andronova, S. Malyshev, and B. Li (2006), Is a shutdown of the thermohaline circulation irreversible?, J. Geophys. Res., 111, D12104, doi:10.1029/2005JD006562.

\section{Introduction}

[2] The importance of the Atlantic thermohaline circulation (THC) in the climate system stems from its two unique properties: its huge northward heat transport and remarkable nonlinear dynamical behavior. Most previous research on the THC focused on issues related to these two properties. For example, it has been shown that the reduction of the northward heat transport induced by the shutdown of the THC can result in considerable cooling over the northern North Atlantic and surrounding regions [Manabe and Stouffer, 1988, 1999; Schiller et al., 1997; Rind et al., 2001; Vellinga and Wood, 2002]. A recent study has suggested that the cooling induced by a shutdown of the THC could be more significant than the $\mathrm{CO}_{2}$-induced warming over the North Atlantic and surrounding regions (M. Vellinga and R. Wood, Impacts of thermohaline circulation shutdown in the twenty-first century, submitted to

\footnotetext{
${ }^{1}$ Climate Research Group, Department of Atmospheric Sciences, University of Illinois at Urbana-Champaign, Urbana, Illinois, USA.

${ }^{2}$ Now at Program in Atmospheric and Oceanic Sciences, Princeton University, Princeton, New Jersey, USA.

${ }^{3}$ Now at Department of Atmospheric, Oceanic and Space Sciences, University of Michigan, Ann Arbor, Michigan, USA.

${ }^{4}$ Department of Ecology and Evolutionary Biology, Princeton University, Princeton, New Jersey, USA.
}

Copyright 2006 by the American Geophysical Union. 0148-0227/06/2005JD006562
Climatic Change, 2005), although most climate model projections indicate that the latter will be dominant during this century when the THC is slowing down. On the basis of contemporary climate model simulations the Third Assessment Report of the Intergovernmental Panel on Climate Change concluded that the shutdown of the THC, as a low probability but high-impact scenario, cannot be completely excluded if the concentrations of greenhouse gases (GHG) continue to increase [Cubasch et al., 2001]. If such a scenario actually occurred, it could be detrimental to the world's environment and economy.

[3] Consideration of the possible future slowdown/shutdown of the THC requires knowledge of the dynamical behavior of the THC. The box ocean model [Stommel, 1961; Titz et al., 2002], the zonally averaged ocean model [Stocker and Wright, 1991], the climate model of intermediate complexity [Ganopolski and Rahmstorf, 2001; Schmittner and Weaver, 2001], the uncoupled OGCM [Marotzke and Willebrand, 1991; Mikolajewicz and Maier-Reimer, 1994; Prange et al., 2002], and the hybrid model [Rahmstorf, 1995; Schmittner et al., 2002] have shown that the THC is a highly nonlinear dynamical system. In response to a sequential increase and then decrease of the freshwater input to the northern North Atlantic, the THC in these simplified models shows bistability, bifurcation, hysteresis, and irreversibility. Such an input of freshwater into the North Atlantic Ocean is what might occur in the future as GHG emissions continue to increase, the Earth warms, 
and freshwater is added to the northern North Atlantic by increasing the excess of precipitation over evaporation there and by the melting of nearby sea ice, mountain glaciers, and the Greenland ice sheet. Indeed, a freshening in high latitudes of the North Atlantic and an increase in salinity in low latitudes has recently been reported [Curry et al., 2003; Schmidt et al., 2004; Curry and Mauritzen, 2005], as has an observed slowdown of the THC at $25^{\circ} \mathrm{N}$ latitude by 30\% from 1957 to 2004 [Bryden et al., 2005].

[4] The dynamical behavior of the THC in the fully coupled AOGCMs hasn't been systematically studied so far because of the large computational expense. To construct the hysteresis curve of the THC as the simplified models have done, the model needs to be integrated for at least several thousand years. This integration with the fully coupled AOGCM is not feasible given the current computational ability. Therefore a different experimental design is necessary to study the dynamical behavior of the THC in the AOGCM. So far, only a few specific freshwater perturbation experiments have typically been performed using AOGCMs. The results from the AOGCMs have confirmed many simulation features obtained by the simplified models. However, some notable differences have also been revealed: (1) More feedbacks associated with complex processes can operate in the AOGCM system [Schiller et al., 1997]; (2) the THC has some different properties in the AOGCM compared with in the simplified models, albeit the difference might result from the experimental designs [Rind et al., 2001]; and (3) the stable "off" mode of the THC simulated by many simplified models appears to be an unstable mode in the AOGCM [Vellinga et al., 2002].

[5] The reversibility of the THC after its shutdown in the fully coupled AOGCM is supported by a recent study by Stouffer et al. [2006]. In that study, the behavior of the THC in response to a freshwater perturbation of $1.0 \mathrm{~Sv}$ (sverdrups; $1 \mathrm{~Sv}=10^{6} \mathrm{~m}^{3} / \mathrm{s}$ ) over the northern North Atlantic is intercompared among simulations from various climate models ranging from the Earth model with intermediate complexity to the fully coupled AOGCM. After the shutdown of the THC induced by a 100-year freshwater input, the elimination of the freshwater perturbation leads to a rapid recovery of the THC in all the AOGCMs that have been integrated long enough for this to occur, except for an early (R30) version of the GFDL AOGCM. Thus the reversible shutdown of the THC is likely a robust characteristic of the fully coupled AOGCMs.

[6] It has been shown that different oceanic vertical and horizontal diffusivities might cause different behavior of the THC in the box ocean model [Longworth et al., 2005], the climate model with intermediate complexity [Schmittner and Weaver, 2001], in the ocean-only model [Prange et al., 2002], and in the fully coupled AOGCM [Manabe and Stouffer, 1999]. However, these studies, as well as most other research on the dynamics of the THC, have been confined to one class of model, either a "simple" model or an AOGCM. Until now little work has been done to compare the behavior of the THC between simple and complex models and study the reasons for the differences. Furthermore, the usage of various models of mixed complexity in the previous research, particularly for the oceanic part, has largely concealed the reason why the THC behaves differently in various models. These models usually have many different treatments of the physical and dynamical processes.

[7] Accordingly, we report here simulations of the THC dynamics with our uncoupled 18-layer OGCM and with it coupled to our 11-layer AGCM. We performed corresponding freshwater perturbation experiments and compared the simulation results, focusing on the differences between these two types of models. As far as the THC simulation is concerned, the uncoupled OGCM is exactly the same as the ocean model in the fully coupled AOGCM. The influence of model individuality is therefore eliminated, and the reasons for the difference, particularly the role of the air-sea feedback in the THC simulation, can be investigated. The results from the present study shed light on the mechanism for the difference identified among the simulations from a hierarchy of climate models. In section 2 the OGCM and coupled AOGCM are described. The results of the control and freshwater perturbation (hosing) simulations are presented and analyzed in section 3 . Conclusions are given in section 4 .

\section{Model Description}

[8] The models used in the present study include an ocean general circulation model [Han, 1984a, 1984b; Schlesinger et al., 1985] and an atmosphere general circulation model [Wang and Schlesinger, 1995; Schlesinger et al., 1997], both of which were developed and used at Oregon State University and the University of Illinois at Urbana-Champaign (UIUC). The UIUC 18-layer OGCM uses depth as vertical coordinate and has a $4^{\circ}$ latitude by $5^{\circ}$ longitude horizontal resolution. The 18 layers range in thickness from $7.6 \mathrm{~m}$ at the surface ocean to $835 \mathrm{~m}$ in the deep ocean. The OGCM is based on the primitive equations and Bryan-Cox numerical scheme [Bryan, 1969]. It calculates the three-dimensional fields of oceanic velocity, temperature and salinity, and the thickness of sea ice. To facilitate the integration, the ocean flow is split into a depth-independent barotropic part and a depth-dependent baroclinic part. The rigid lid condition is used at the ocean surface to allow a long integration time step, on the order of hours. The vertical viscosity and diffusivity are calculated according to a Richardson number-dependent scheme [Pacanowski and Philander, 1981]. A thermodynamic sea ice model is embedded in the 18-layer OGCM to predict sea ice thickness and coverage, using the thermodynamic equation over the ocean surface.

[9] The standard version of the ocean-only model is run with prescribed climatological fluxes at the air-sea interface. The ocean-only model updates its boundary conditions (wind stress, heat, and freshwater fluxes) every 5 days. The mixed boundary condition is also separately used for the ocean-only model as an alternative surface boundary condition. With this boundary condition, the freshwater flux from the atmosphere is prescribed and the heat flux is calculated proportional to the difference between the prescribed atmospheric temperature and the simulated sea surface temperature. The 18-layer OGCM has been integrated for more than one thousand years with these boundary conditions.

[10] The UIUC 11-layer troposphere/lower-stratosphere (TLS) GCM calculates the velocity, temperature, water vapor, and cloud water for 11 unevenly spaced layers in the troposphere and lower stratosphere; the surface pressure; 


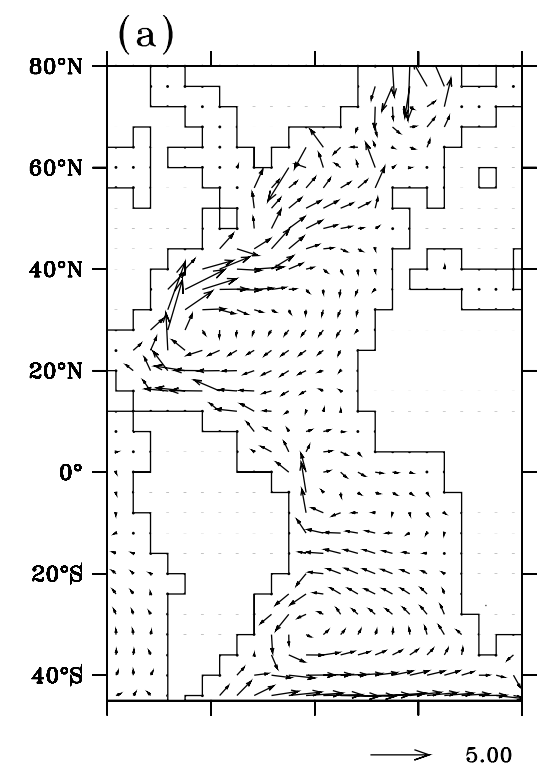

(b)
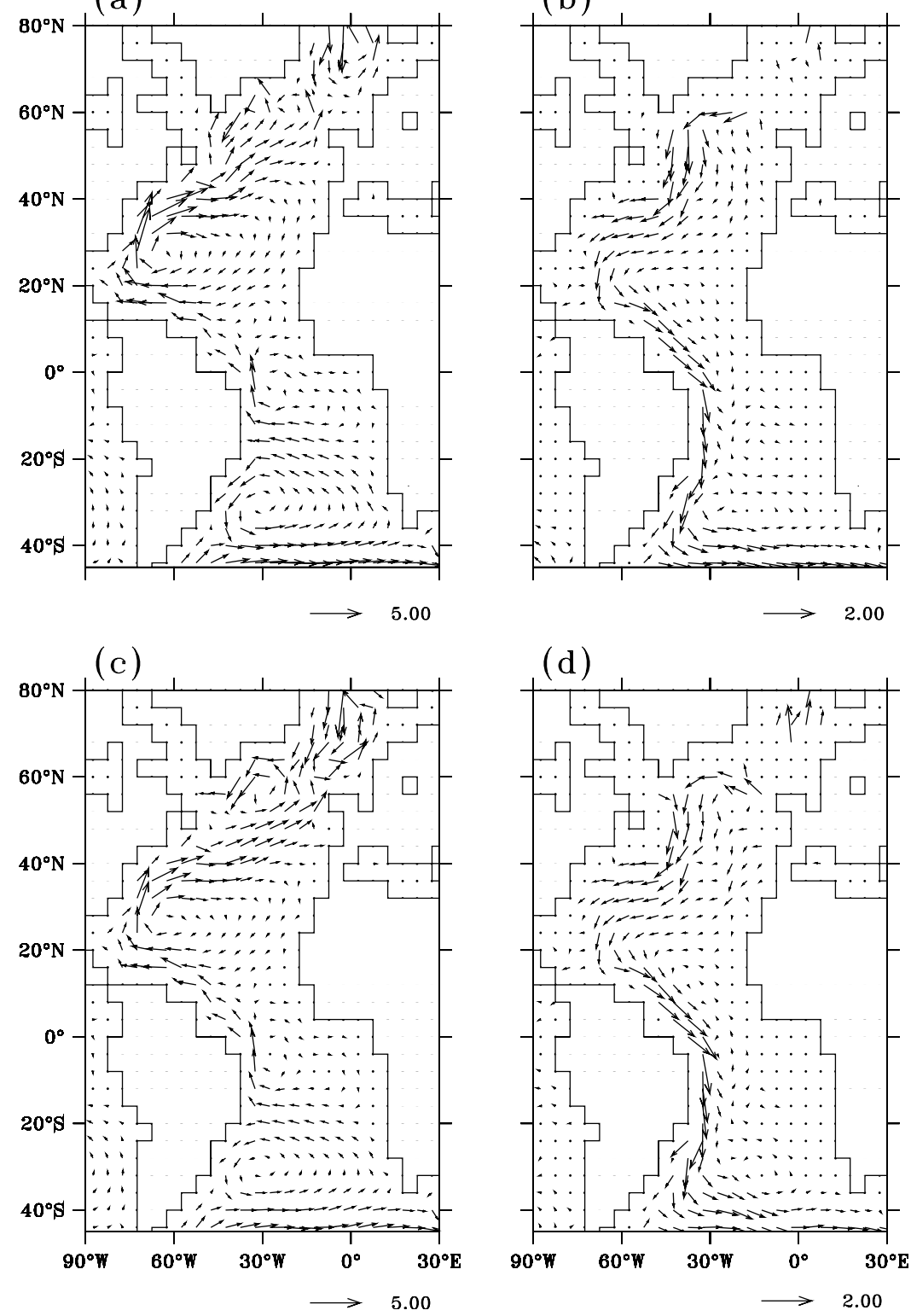

(d)

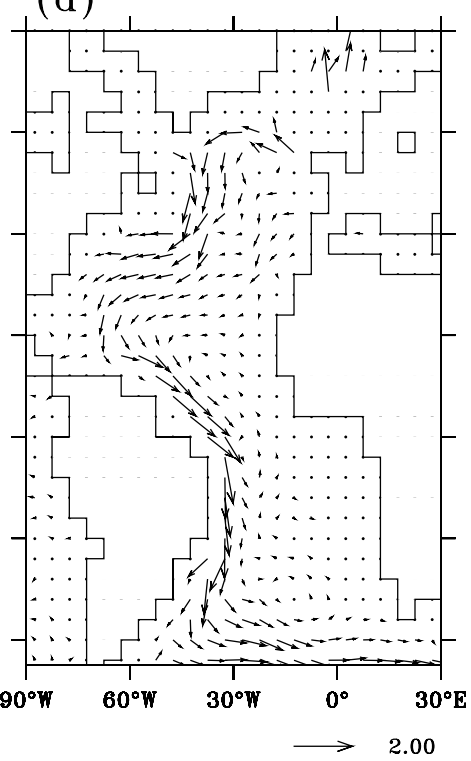

Figure 1. Atlantic Ocean currents simulated by the University of Illinois at Urbana-Champaign (UIUC) uncoupled OGCM with mixed boundary conditions and by the UIUC coupled AOGCM (50-year mean). Units are cm/s. (a, b) Uncoupled OGCM; (c, d) AOGCM. Figures 1a and 1c show the upper ocean (mean of $0-1000 \mathrm{~m}$ ); Figures $1 \mathrm{~b}$ and $1 \mathrm{~d}$ show the deep ocean (mean of 1000-3000 m).

the temperature, soil water, and snow mass on land; and many other quantities, including the temperature and water vapor content of the air near the surface, the cloud amount and cloud water and ice, rainfall, and snowfall. The horizontal distribution of dependent variables in the model is staggered according to the $B$ grid to simulate the process of geostrophic adjustment [Arakawa and Lamb, 1977], and the model uses finite differences that conserve the total atmospheric mass, total energy under adiabatic and frictionless motion, and enstrophy (mean square vorticity) and kinetic energy for the nondivergent component of the wind field [Arakawa, 1966]. The model has a standard horizontal resolution of $4^{\circ}$ latitude by $5^{\circ}$ longitude and vertically extends from the Earth's surface to $50 \mathrm{hPa}$. It uses normal- ized pressure, $\sigma$, as its vertical coordinate and has realistic geography and topography.

[11] The adiabatic, frictionless terms in the governing prognostic equations of the TLS GCM are marched forward in time in a 1-hour cycle using a combination of Matsuno and leapfrog time integration steps, with a basic time step of 6 minutes. The diabatic and frictional terms in the governing prognostic equations are calculated once per hour. A new parameterization of infrared radiation developed by Chou and Suarez [1994] was implemented into the 11-layer model by Yang [2000] to compute the absorption and emission of terrestrial radiation due to water vapor, carbon dioxide, and ozone.

[12] The 11-layer AGCM and the 18-layer OGCM have been coupled together using a serial coupling procedure. 

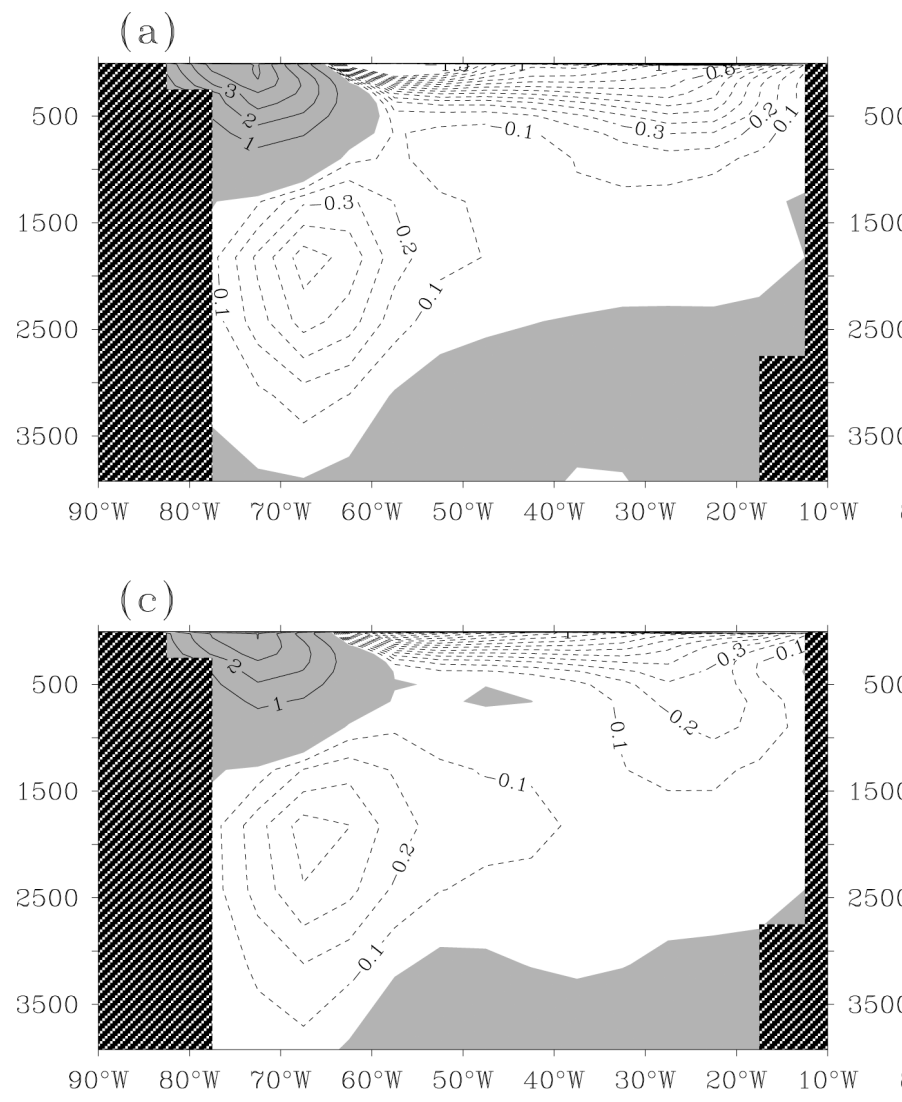

(b)

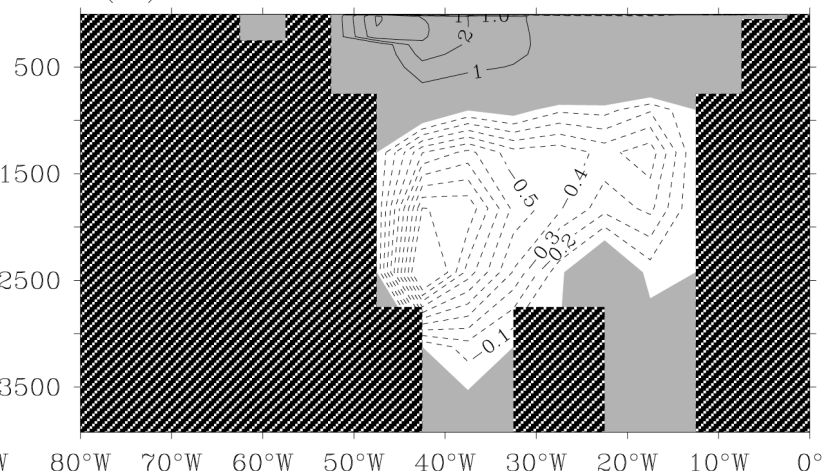

(d)

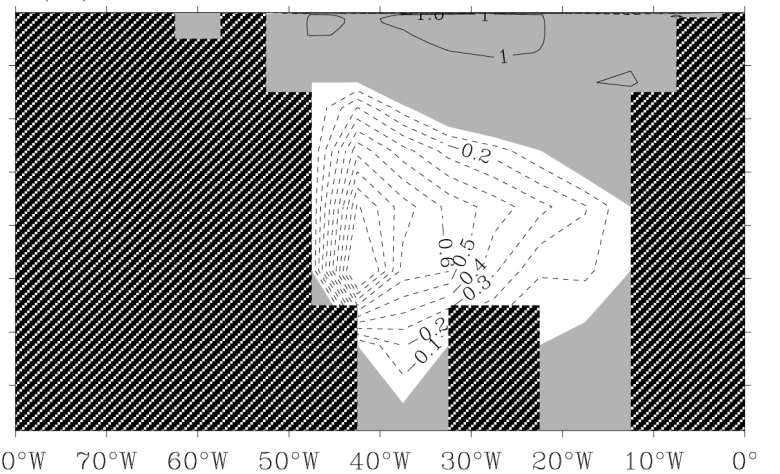

Figure 2. Two vertical cross sections in the Atlantic Ocean simulated by the uncoupled OGCM with mixed boundary conditions and by the AOGCM (50-year mean). Positive values (shaded) represent northward flow. Units are cm/s. (a, b) Uncoupled OGCM; (c, d) AOGCM. Figures 2a and 2c show 30 ${ }^{\circ}$; Figures $2 \mathrm{~b}$ and $2 \mathrm{~d}$ show $50^{\circ} \mathrm{N}$. The depth is in meters.

The atmospheric model and the oceanic model are integrated forward alternately, with the models exchanging information once per day. Daily mean fluxes of heat, water, and momentum at the ocean surface are calculated by the atmospheric model and passed to the oceanic model, and the sea surface temperature (SST) and sea ice thickness from the oceanic model are passed to the atmospheric model as its ocean surface boundary conditions. The coupled AOGCM is flux corrected for SST and sea surface salinity (SSS) to better simulate the present climate. After the spin-up of the fully coupled AOGCM a multicentury control run was performed.

\section{Simulation Results}

\subsection{The THC in the Control Climate}

[13] In this section the THC and associated oceanic features are analyzed and compared between the control runs of the uncoupled OGCM with the mixed boundary conditions and the AOGCM. The control climate of the atmosphere simulated by the coupled model is very close to what has been described before [Wang and Schlesinger, 1995].

[14] Figure 1 shows the ocean currents in the control runs of the uncoupled OGCM and the AOGCM. In both models the component currents of the THC are well simulated. The
Gulf Stream and its extension, the North Atlantic Current (NAC), are very pronounced in the upper ocean and transport a large amount of warm and salty seawater from the subtropical region all the way into the Norwegian Sea (Figures 1a and 1c). The slow southward flow of the North Atlantic subtropical gyre provides a partial return of the seawater mass. The East Greenland Current and the subpolar gyre are more notable and better organized in the AOGCM than in the uncoupled OGCM. The stronger East Greenland Current in the AOGCM transports more fresh Arctic seawater southward, weakening the North Atlantic Deep Water (NADW) formation in the AOGCM (shown later). At about $60^{\circ} \mathrm{N}$ of the North Atlantic, there is a clear convergence of upper ocean flows in both models which results in the sinking motion there. Deep convection and deep water formation are induced by intense heat loss, forming the deep ocean currents that flow all the way to the Southern Ocean (Figures $1 \mathrm{~b}$ and 1d).

[15] Figure 2 displays two vertical cross sections in the North Atlantic from simulations by the uncoupled OGCM with the mixed boundary conditions and by the AOGCM. At $30^{\circ} \mathrm{N}$, two types of circulation are present: the horizontal wind-driven gyre circulation within the upper $500 \mathrm{~m}$ and the vertical THC (Figures 2a and 2c). According to mass conservation, the Gulf Stream participates in both circulations. The THC mainly consists of two western boundary 

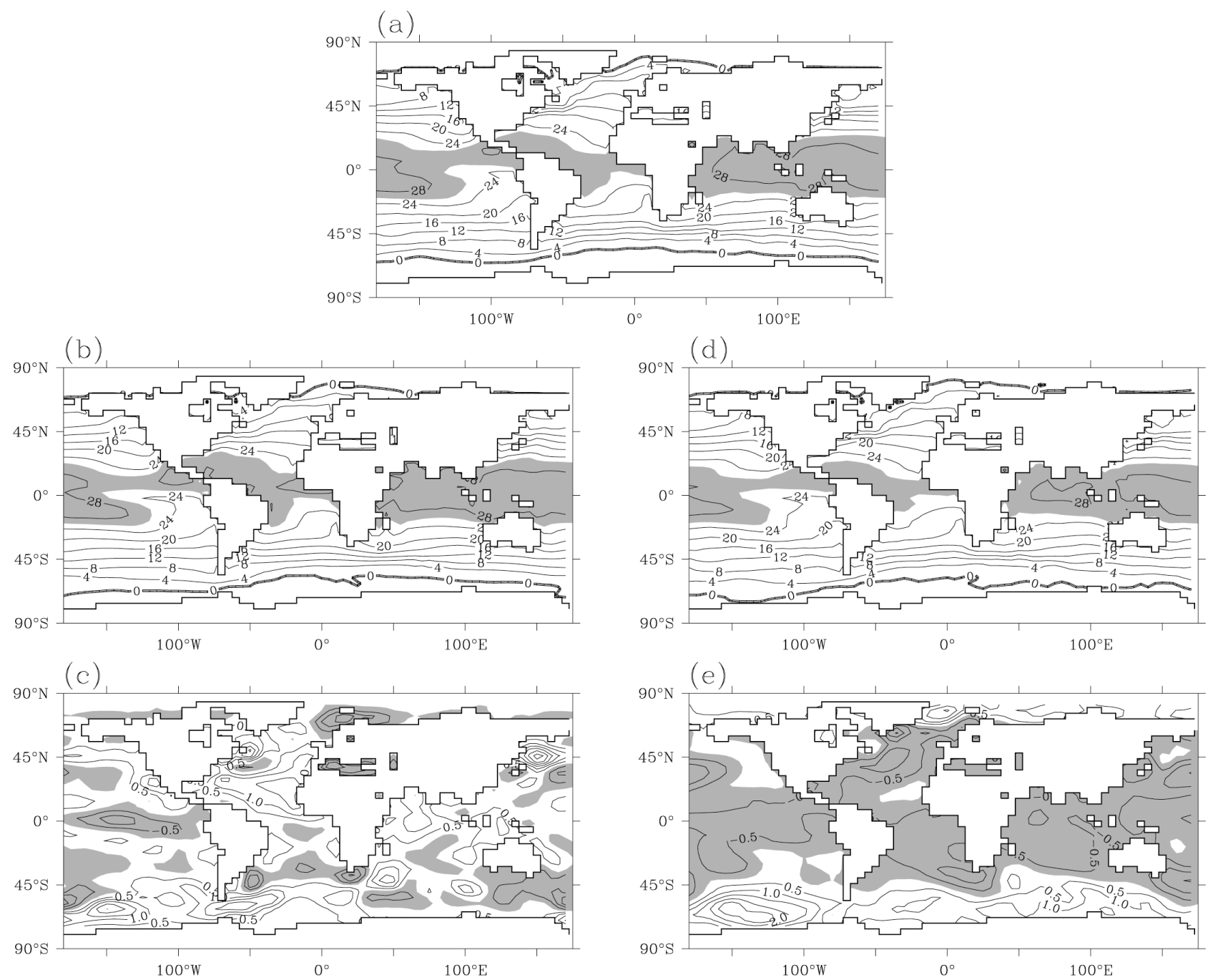

Figure 3. Geographical distribution of SST. (a) Observation [Levitus and Boyer, 1994]; (b) Simulation by the uncoupled OGCM; (c) Difference between the OGCM simulation and the observation; (d) Simulation by the AOGCM (50-year mean); (e) Difference between the AOGCM simulation and the observation. Units are ${ }^{\circ} \mathrm{C}$. Temperatures greater than $26^{\circ} \mathrm{C}$ are shaded in Figures $3 \mathrm{a}, 3 \mathrm{~b}$, and $3 \mathrm{~d}$. Negative values are shaded in Figures $3 \mathrm{c}$ and $3 \mathrm{e}$.

currents with northward flow in the upper ocean and southward flow at depth. At $50^{\circ} \mathrm{N}$, the vertical THC is the dominant circulation pattern (Figures $2 \mathrm{~b}$ and $2 \mathrm{~d}$ ). Both the upper ocean current and the deep ocean current become basin-wide. The deep ocean current is stronger and located at a deeper level at $50^{\circ} \mathrm{N}$ than at $30^{\circ} \mathrm{N}$, indicating a gradual upwelling and weakening of the current as it flows southward. A difference between Figures $2 b$ and $2 d$ is the magnitude of the northward component of the NAC in the upper ocean. It is larger in the uncoupled OGCM, with the core closer to the western boundary. However, the northward flow reaches a greater depth in the AOGCM. The different magnitude of the northward component of the $\mathrm{NAC}$ is a result of the different strengths of the THC in the two model simulations. In addition, the NAC flows more northward at $50^{\circ} \mathrm{N}$ in the uncoupled OGCM (Figure 1a), whereas it flows more eastward in the AOGCM (Figure 1c). The zonally averaged meridional overturning stream func- tion (shown later) indicates that the THC is simulated reasonably well in the control runs of both models.

[16] The successful simulation of the THC is attributable to the realistic simulation of SST and SSS in both models. A long-term, stable SST and SSS are also important criteria for validating the uncoupled OGCM and coupled AOGCM before the performance of the freshwater perturbation experiments. Figures 3 and 4 show the geographical distributions of SST and SSS from both observations and simulations. The bias of the simulated SST (Figures 3c and $3 \mathrm{e}$ ) is less than $0.5^{\circ} \mathrm{C}$ over most of the ocean. The AOGCM tends to have a cold bias whereas the uncoupled OGCM has an overall warm bias. The relatively large values at high latitudes around Antarctica are related to the sea ice simulation. The SSS simulation in the uncoupled OGCM (Figures $4 \mathrm{~b}$ and $4 \mathrm{c}$ ) is generally better than that in the AOGCM (Figures 4d and 4e). However, the bias in the AOGCM simulation mainly comes from the Pacific Ocean. 


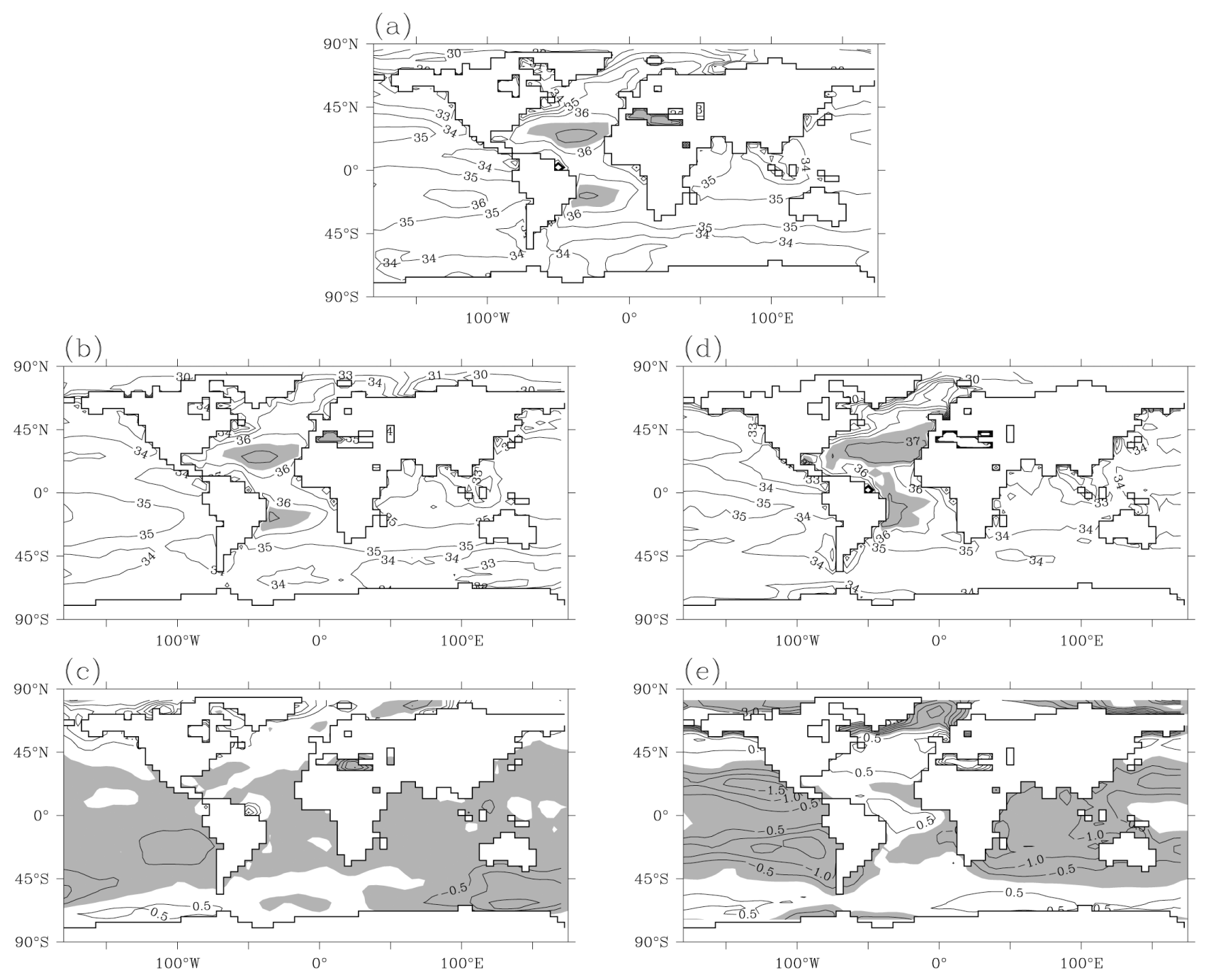

Figure 4. Geographical distribution of SSS. (a) Observation [Levitus and Boyer, 1994]; (b) Simulation by the uncoupled OGCM; (c) Difference between the OGCM simulation and the observation; (d) Simulation by the AOGCM (50-year mean); (e) Difference between the AOGCM simulation and the observation. Units are psu. Salinities greater than 36.5 psu are shaded in Figures $4 a, 4 b$, and $4 d$. Negative values are shaded in $4 \mathrm{c}$ and $4 \mathrm{e}$.

The important features in the Atlantic Ocean such as the maximum SSS in the subtropical Atlantic and the northward intrusion of high-salinity seawater into the Nordic Seas (Figures $4 \mathrm{~b}$ and $4 \mathrm{~d}$ ) are in good agreement with observations (Figure 4a) in both models. Manabe and Stouffer [1988] demonstrated that without this high-salinity tongue over the northern North Atlantic, a vigorous THC cannot be obtained in the coupled AOGCM.

[17] Figure 5 plots the time series of the global mean, root-mean-square difference (RMSD) between the simulated and observed SST and SSS. The RMSD curves show a stable control climate during the multicentury integration period by the AOGCM. In most years the RMSD of SST is less than $1{ }^{\circ} \mathrm{C}$, while the RMSD of SSS is about 1.3 practical salinity units (psu) after a long-term integration. The relatively large bias of the salinity occurs from the lack of direct atmospheric feedback on salinity. As shown in Figure 4e, however, the salinity bias mainly comes from the Pacific and Indian Oceans. It is less than 0.5 psu in the Atlantic Ocean, which is good enough for the freshwater perturbation experiments. In general, the SST simulation is better in the low and middle latitudes than the high latitudes, while the SSS simulation in the Atlantic is closer to observation than in the Pacific and Indian Oceans. Both SST and SSS are stable during the multicentury integration.

\subsection{Freshwater Perturbation Experiments}

[18] The freshwater perturbation experiments with the uncoupled OGCM were performed by very slowly increasing and then decreasing the external freshwater addition to the North Atlantic between $50^{\circ} \sim 70^{\circ} \mathrm{N}$ latitudes [Rahmstorf, 1995]. The freshwater perturbation changes at a rate of $0.2 \mathrm{~Sv}$ per 1000 years (Figure 6). Although the setup of the experiment is a transient run, the THC is always in quasi-equilibrium with the external freshwater forcing because of the extremely slow change of the perturbation flux. Therefore the entire hysteresis loop of the THC can be constructed. To facilitate comparison with the 


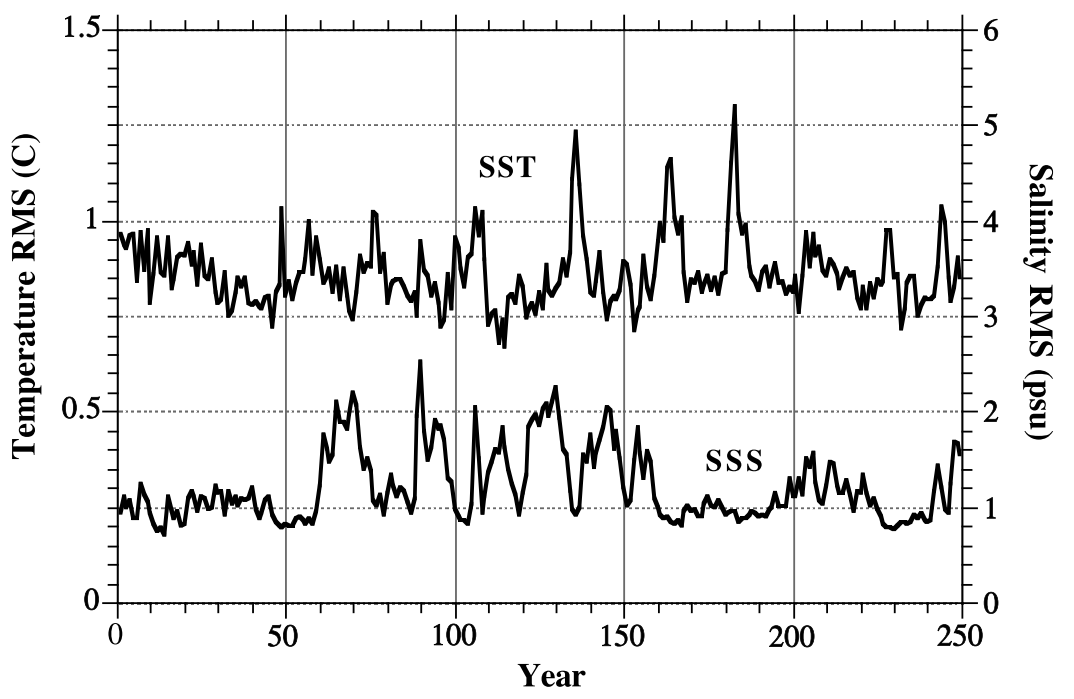

Figure 5. Time series of the global mean, root-mean-square difference between the AOGCM simulated and observed SST and SSS.

AOGCM simulations and completely eliminate the influence of the experimental design, a fixed $0.6 \mathrm{~Sv}$ freshwater perturbation experiment, identical to that in the AOGCM described below, was specially carried out using the ocean-only model.

[19] The set of AOGCM simulations was performed for fixed freshwater addition ("hosing") and removal ("dehosing") rates over the same latitude band in the North Atlantic as for the OGCM-only simulations. We use the word "dehosing" here to indicate the reduction of the freshwater addition following the hosing experiments, either to a smaller value or to zero. Two groups of freshwater perturbation experiments were carried out to test the response of the THC. The first group includes three hosing experiments starting from the 30th year of the control run. Perturbation freshwater fluxes of $0.05,0.1$, and $0.3 \mathrm{~Sv}$ were uniformly input into the perturbation region in separate experiments. The 110th year of the control run was chosen as the initial condition for the second group. This group consists of three hosing experiments $(0.1,0.3$, and $0.6 \mathrm{~Sv})$ and two dehosing experiments. Two dehosing experiments starting from the shutdown state of the THC, induced by the $0.6 \mathrm{~Sv}$ freshwater addition, include a moderate reduction of the perturbation flux from 0.6 to $0.3 \mathrm{~Sv}$ and the total elimination of the $0.6 \mathrm{~Sv}$ freshwater addition. Table 1 summarizes all the experiments performed with the uncoupled OGCM and AOGCM.

[20] Figure 7 plots the time evolution of THC intensity for the two groups of freshwater perturbation experiments with the AOGCM. The behavior of the THC in the uncoupled OGCM and AOGCM under the identical freshwater forcing is also compared in Figure 8. In the present study, the intensity of the THC is defined as the maximum meridional stream function value in the North Atlantic, excluding the surface layer.

[21] The long-term average of the THC intensity in the control run of the AOGCM is about $18 \mathrm{~Sv}$ (Figure 7), which is consistent with the recent estimate using high-quality hydrographic data obtained during the World Ocean Circulation Experiments [Ganachaud and Wunsch, 2000]. For comparison, the THC intensity in the uncoupled OGCM with mixed boundary conditions is about $23 \mathrm{~Sv}$ (Figure 8). This intensity is larger than the recent estimate, but still within the range of the simulated values from contemporary climate models [Gregory et al., 2005; Stouffer et al., 2006].

[22] There are substantial variations of the THC intensity on the decadal timescale in the control run and the small freshwater perturbation $(0.05$ and $0.1 \mathrm{~Sv})$ experiments of the AOGCM [Delworth et al., 1993]. However, these variations are greatly inhibited in the large perturbation $(0.3$ and $0.6 \mathrm{~Sv})$ experiments (Figure 7). By contrast, there is no variability of the THC intensity in the control run and the hosing experiments of the uncoupled OGCM (Figure 8). The uncoupled OGCM doesn't incorporate an atmospheric GCM that causes variations of the air-sea fluxes. The multidecadal variations of the THC are therefore not excited in the uncoupled OGCM.

[23] The weakening of the THC in the AOGCM in response to a small freshwater perturbation such as 0.05

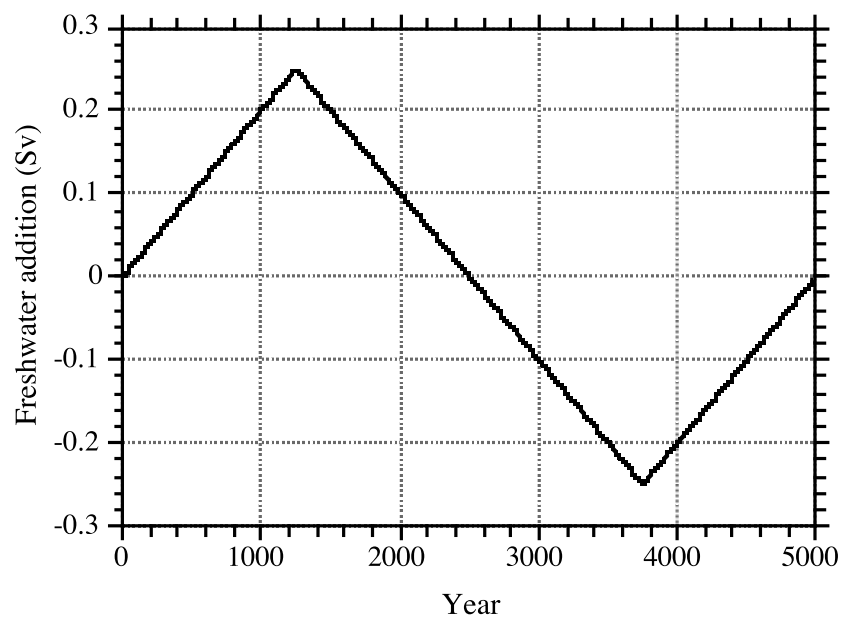

Figure 6. Time-dependent freshwater perturbation in the uncoupled OGCM experiments. The freshwater perturbation changes linearly at a rate of $0.2 \mathrm{~Sv}$ per 1000 years. 


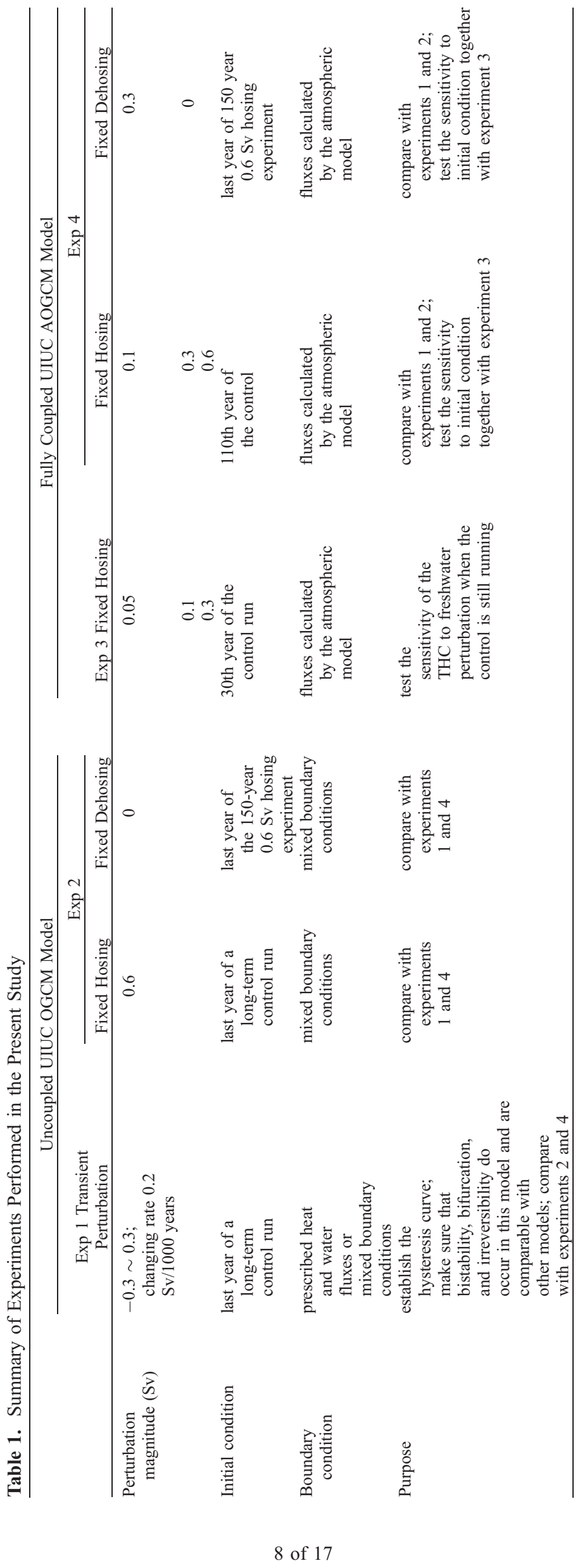



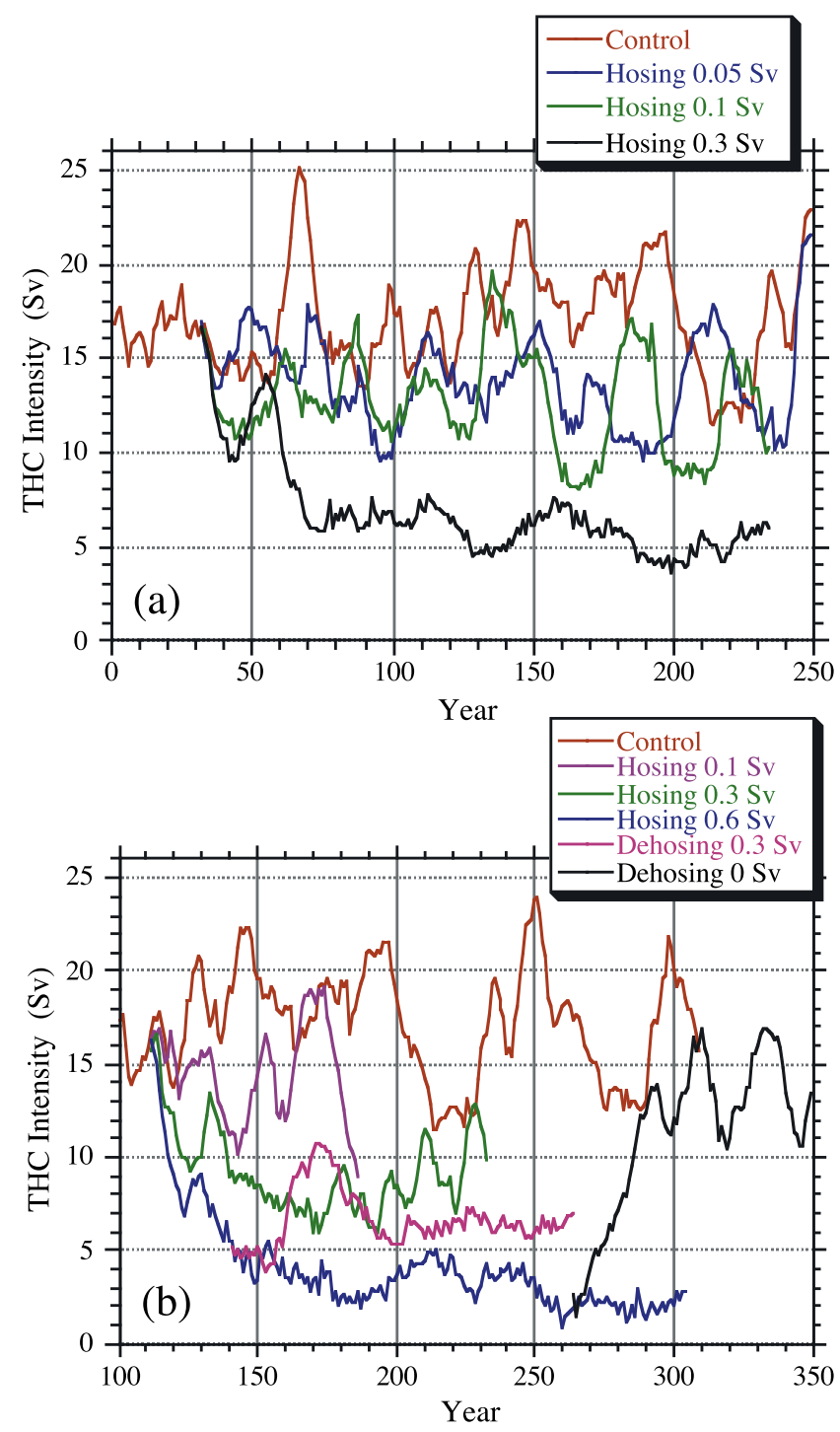

Figure 7. Freshwater perturbation experiments using the coupled AOGCM. (a) First group; (b) second group.

and $0.1 \mathrm{~Sv}$ is moderate and can better be detected using the long-term mean. However, a large freshwater perturbation leads to a rapid and significant slowdown of the THC. The $0.6 \mathrm{~Sv}$ perturbation flux is sufficient to shut down the THC. The fundamental structure of the THC seen in the control disappears at the end of the hosing period (see Figure 11d in section 3.3). The response time of the THC to the $0.6 \mathrm{~Sv}$ freshwater perturbation is about 50 years in the AOGCM and 20 years in the uncoupled OGCM, indicating different freshwater sensitivity of the THC (Figure 8). Both timescales are much shorter than the advection process of the deep ocean. It has been shown that the anomalies of the THC can propagate from the high latitudes of the North Atlantic to the equator on a timescale of months by stimulating Kelvin and Rossby waves in the ocean [Johnson and Marshall, 2002]. In the small-perturbation experiments, the response time of the THC intensity is relatively longer.

[24] The most important result for the $0.6 \mathrm{~Sv}$ freshwater perturbation experiment in the AOGCM is that once the perturbation is reduced, the THC immediately starts to recover (Figure 7b). Like the shutdown process, the startup process is also fast and can be completed within about 50 years. For the dehosing experiment in which the perturbation is totally eliminated, the THC basically reintensifies to the original strength. In contrast, the THC keeps inactive in the uncoupled OGCM with mixed boundary conditions even after the $0.6 \mathrm{~Sv}$ freshwater perturbation is eliminated (Figure 8). This indicates that the THC in the uncoupled OGCM has changed from a stable state with the circulation on to another stable state with the circulation off.

\subsection{The Dynamical Behavior of the THC}

[25] In this section the detailed dynamical behavior of the THC is further investigated on the basis of the results from the freshwater perturbation experiments. Figures $9 \mathrm{a}$ and $9 \mathrm{~b}$ show the strength of the THC as a function of the freshwater added and then removed from the North Atlantic as simulated by the uncoupled OGCM with the two commonly used boundary conditions: (1) prescribed heat and freshwater fluxes from the atmosphere and (2) calculated heat and prescribed freshwater fluxes from the atmosphere (mixed boundary conditions). Both simulations display similar and notable features. There is a pronounced hysteresis loop in which the THC, after shutdown, can be restarted only after the freshwater addition is eliminated and changed into a freshwater extraction. Three equilibria of the THC coexist under the present-day freshwater forcing. Points $\mathrm{A}$ and $\mathrm{E}$ correspond to two active THC modes while point $\mathrm{C}$ is an inactive THC mode. The different intensity between points $\mathrm{A}$ and $\mathrm{E}$ is caused by the switch on (point $\mathrm{E}$ ) and off (point A) of the deep convection in the Labrador Sea. Points B and $\mathrm{D}$ are thresholds along the hysteresis curves. Beyond these critical points, the THC undergoes a rapid transition between the active and inactive modes. All of these features indicate a remarkable nonlinearity of the THC in the oceanonly model, which results from the domination by the positive feedbacks in the THC system.

[26] The oceanic salinity advection feedback (Figure 10a) is among the most important positive feedbacks in both versions of the uncoupled OGCM. The reduced northward salinity transport induced by a weakened THC weakens the THC further [Stommel, 1961]. In contrast, the oceanic temperature advection feedback (Figure 10b) is an important negative feedback. The reduction of the northward heat transport induced by the weakening of the THC causes a decrease in high-latitude SST and an increase in the surface seawater density of the northern North Atlantic in the ocean-only model with prescribed fluxes. This density increase partially compensates the density decrease induced by the surface freshening, thereby stabilizing the active THC or destabilizing the inactive THC [Rahmstorf and Willebrand, 1995]. This negative feedback cannot occur in the ocean-only model with mixed boundary conditions because the SST has been constrained to the prescribed values. Thus the THC in the ocean-only model with mixed boundary conditions is more sensitive to the freshwater perturbation than is this model with prescribed fluxes. Accordingly, the entire hysteresis loop of Figure 9b is shifted toward the left in comparison with the hysteresis loop of Figure 9a. 


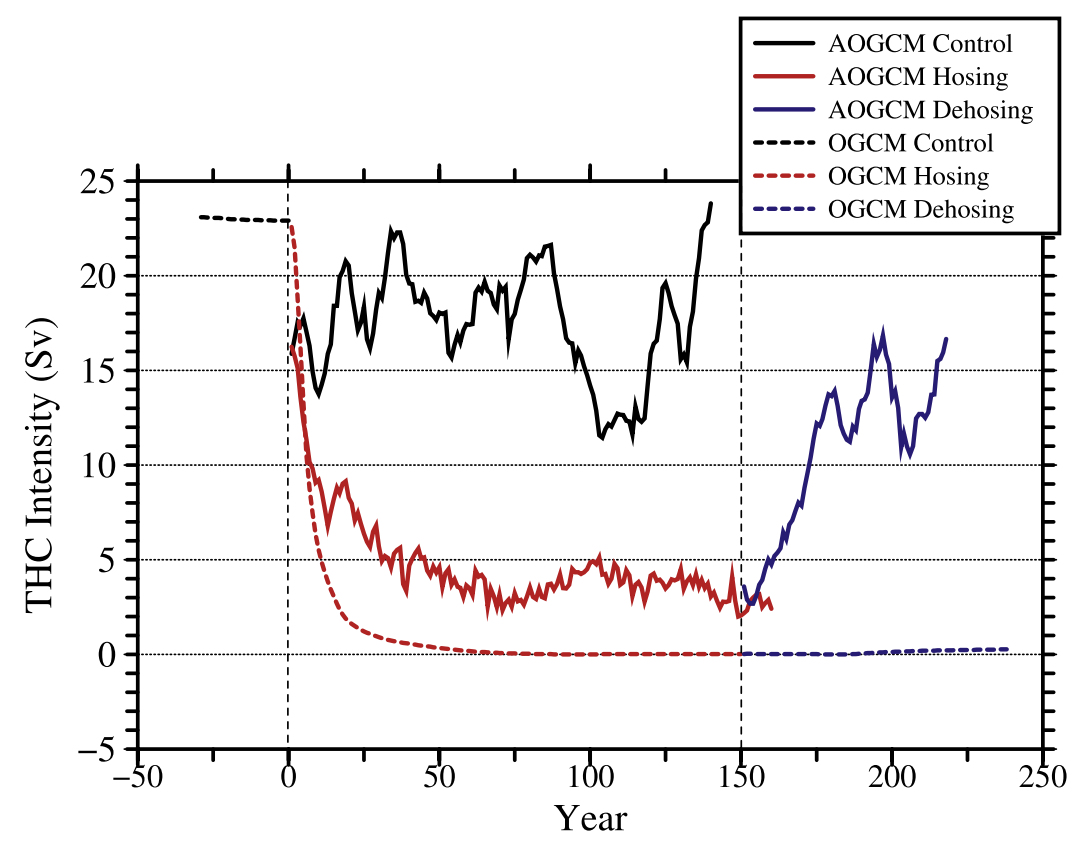

Figure 8. Time series of the THC intensity in response to a 150-year $0.6 \mathrm{~Sv}$ freshwater input and the removal of the perturbation thereafter. To facilitate the comparison, the starting points of the experiments in both models are shown as the first year.

[27] Figure 9c shows the steady state strength of the THC as a function of the increase (red points) and then decrease (blue points) in freshwater added to the North Atlantic as simulated by the fully coupled AOGCM. In contrast to the uncoupled OGCM, the AOGCM does not produce a pronounced hysteresis loop when the freshwater added to the North Atlantic is increased until shutdown occurs and is then reduced. Instead, once the freshwater addition is reduced from its shutdown value, the THC restarts. Furthermore, the relation between the THC intensity and the change in freshwater addition is roughly linear throughout the entire range of freshwater addition. It can also be seen that the freshwater addition required to shut down the THC is much larger in the AOGCM $(0.6 \mathrm{~Sv})$ than in the uncoupled OGCM (0.2 Sv).

[28] It should be noted that the behavior of the THC in the transient runs may be sensitive to the freshwater forcing rate. Under a slowly varying forcing, the model can feel the (saddle node) bifurcation, and the abrupt shift beyond the critical points can be seen (Figures 9a and 9b). In response to a fast freshwater input, however, a model may be insensitive to the bifurcation point, and the THC could show a linear response. However, none of these influence the comparison between Figures 9a, 9b, and 9c because all the points and curves in Figure 9 are equilibrium or quasiequilibrium responses of the $\mathrm{THC}$ to freshwater forcing. Since Figure 9c gives discrete points, the comparison would be better and more comprehensive after the construction of the continuous curve for the AOGCM, which we cannot do at this time. As confirmed by Figure 8, one notable difference in Figure 9 between the uncoupled OGCM and the AOGCM is the reversibility/irreversibility of the THC, which is the focus of the present study. The "off" mode of the THC is an unstable mode in the AOGCM but is a stable mode in the uncoupled OGCM. In the AOGCM once the freshwater addition is reduced from its shutdown value, the THC restarts.

[29] Figure 11 compares the evolution of the meridional overturning stream function, which shows the rotational part of the velocity field, in the Atlantic simulated by the uncoupled OGCM and the AOGCM. The top two panels (Figures 11a and 11b) display the stream function patterns of the control run. It is apparent that sinking motion takes place between $50^{\circ} \sim 60^{\circ} \mathrm{N}$. There is an intense interhemisphere exchange of seawater mass associated with the THC, leading to an uniformly northward heat transport in the Atlantic Ocean. Beneath the THC cell, a counterclockwise bottom circulation exists. Another counterclockwise circulation cell appears north of $50^{\circ} \mathrm{N}$. This cell is more vigorous in the AOGCM because of the stronger East Greenland Current. The perturbation freshwater flux of $0.6 \mathrm{~Sv}$ is sufficient to shut down the THC in both models (Figures 11c and 11d). However, the circulation patterns after the shutdown of the THC are quite different in the two models. In the uncoupled OGCM, a reversed circulation develops in the upper South Atlantic and extends northward (Figure 11c). This cell vertically connects with the bottom circulation cell that changes little during the hosing period. In the AOGCM, however, such a reversed circulation cell does not exist. There is a positive region connecting to the surface Ekman cell in the North Atlantic (Figure 11d). However, the values in this positive region are very close to zero, indicating a shutdown state of the THC. The bottom circulation intensifies and extends upward during the hosing period. After the elimination of the freshwater perturbation, the $\mathrm{THC}$ cell reestablishes rapidly in the AOGCM (Figure 11f), whereas it keeps inactive in the uncoupled OGCM (Figure 11e). Hence the THC simulated 
by an ocean general circulation model responds very differently depending on whether it is uncoupled or coupled to an atmosphere general circulation model, with the former giving an irreversible THC shutdown and the latter giving a reversible THC shutdown.

\subsection{Crucial Feedback Processes}

[30] It is important to examine the reason why the THC in the fully coupled AOGCM has a different dynamical
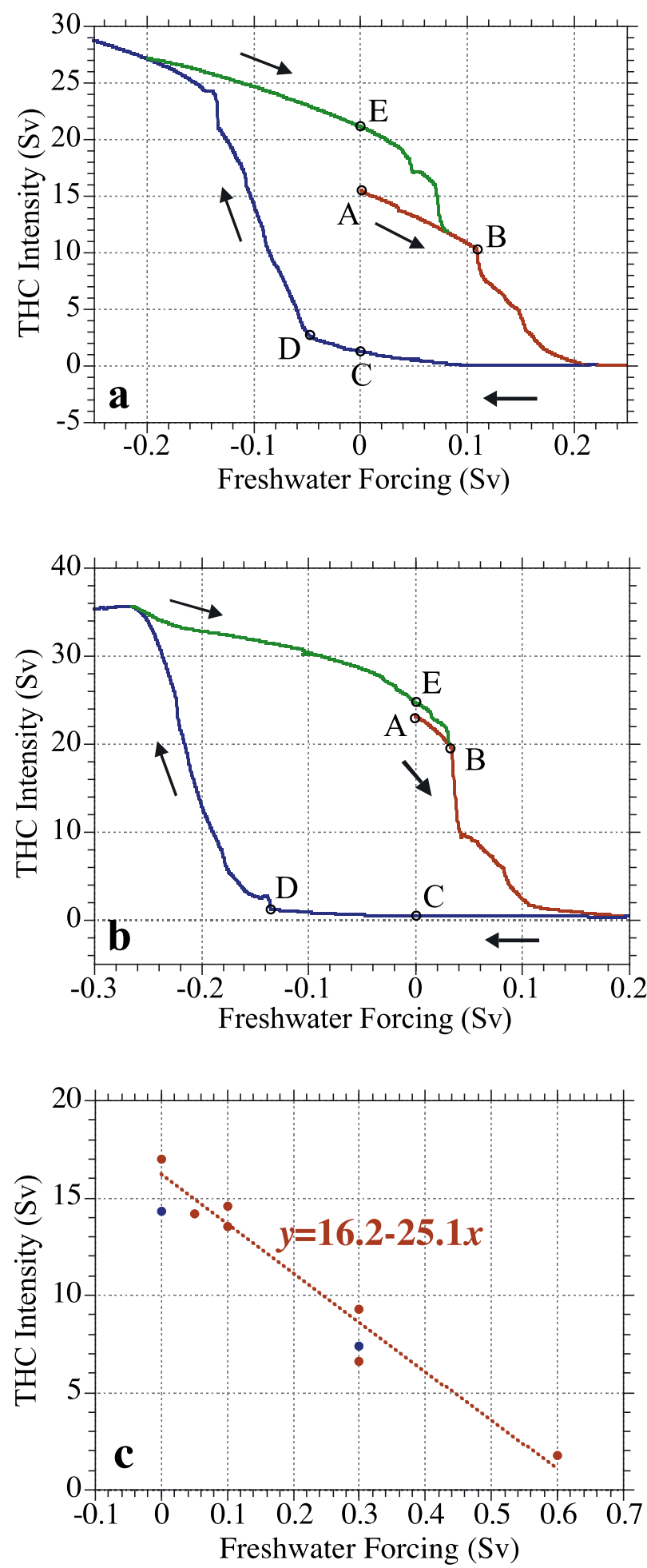

behavior from that of the uncoupled OGCM. The THC is driven by oceanic convection in the high latitudes of the North Atlantic. A high potential density of the surface seawater is a prerequisite for the occurrence of deep convection. In addition, it has been shown that the intensity and circulation pattern of the THC critically depend on the differential in seawater potential density between the northern North Atlantic and Southern Ocean [Saenko et al., 2003]. The basin-averaged salinity in the Atlantic and the salt input/output across $30^{\circ} \mathrm{S}$ of the Atlantic Ocean are important factors to determine whether there is a THC in the Atlantic and how it behaves [Gregory et al., 2003; Seidov and Haupt, 2003, 2005; De Vries and Weber, 2005].

[31] After the shutdown of the THC, two distinctly different circulation patterns are obtained in the upper South Atlantic in the uncoupled OGCM and AOGCM simulations. A reversed (counterclockwise) cell is very pronounced in the uncoupled OGCM (Figure 11c), while this reversal of the THC doesn't occur in the AOGCM. Table 2 lists the salt transport across $30^{\circ} \mathrm{S}$ of the Atlantic for the "on" and "off" modes of the THC in the two model simulations. Clearly, the salt transport in the uncoupled OGCM changes sign after the shutdown of the THC because of the THC reversal. The reversed cell transports a large amount of salt across $30^{\circ} \mathrm{S}$ out of the Atlantic basin (the region that has definite east-west boundaries). In addition, the strong upwelling in the entire upper Atlantic associated with the reversed cell brings less saline water from the deeper ocean to shallow levels. Both the southward salt transport and the strong upwelling induced by the THC reversal facilitate the salinity decrease in the Atlantic and the southward spread of the perturbation freshwater from the northern North Atlantic (shown later). Consequently, the basin-averaged salinity decreases considerably in the upper Atlantic from 33.8 to 33.0 psu (Table 3 ). The latter is close to the mean salinity in the Pacific (32.9 psu) where no deepwater formation takes place. Given such a low salinity in the Atlantic, the THC cannot reintensify in the uncoupled OGCM. In contrast, the salt transport is still northward at $30^{\circ} \mathrm{S}$ in the AOGCM after the shutdown of the THC, although the magnitude is greatly reduced. No upwelling takes place in the upper Atlantic. The higher-than-normal salinity in the Atlantic is pronounced even for the "off" (hosing) state of the THC

Figure 9. Stability diagrams of the THC established by the uncoupled OGCM and the coupled AOGCM. (a) OGCM with prescribed surface heat and salinity fluxes; (b) OGCM with prescribed salinity flux and calculated heat flux (mixed boundary condition); (c) AOGCM (50-year mean). Red, blue, and green represent the increase in freshwater addition, the subsequent decrease in freshwater addition after the THC is shut down, and the following increase in freshwater addition. There is no green in Figure 9c because no hosing experiment was performed again after the full recovery of the THC in the dehosing experiment. The origin of the $x$ axis represents the "present-day" freshwater flux. The red (solid) points in Figure 9c indicate the steady state intensity of the THC in Figures 7a and $7 \mathrm{~b}$, while the blue points (circles) are from the dehosing integrations. The red dashed line is the linear fit based on the red points. 
(a)

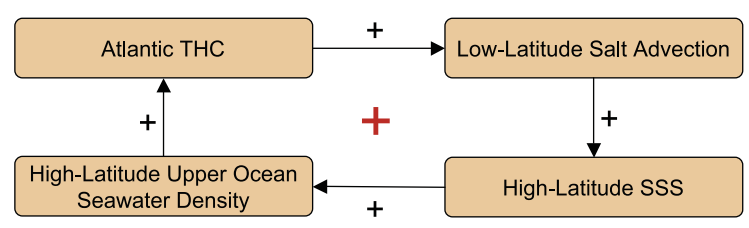

(b)

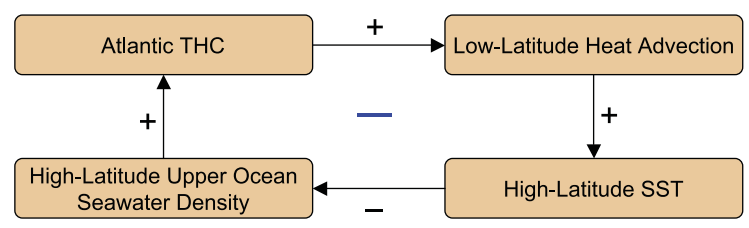

(c)

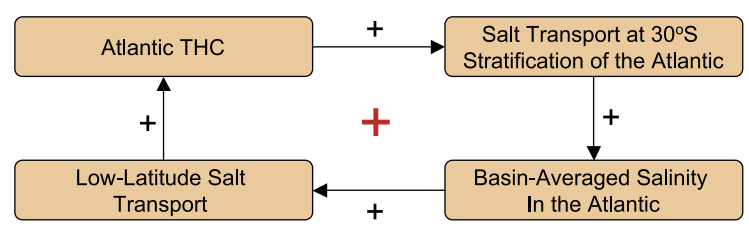

(d)

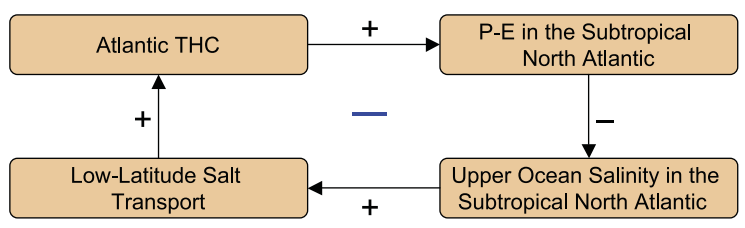

Figure 10. Schematic illustration of the feedback processes in the simulations initiated by external freshwater addition to the North Atlantic Ocean. The signs attached to the arrows indicate the correlation between the changes in the quantity of the outgoing box with that of the ingoing box. The red "plus" indicates an overall positive feedback of a loop and the blue "minus" indicates an overall negative feedback of a loop. (a) Oceanic salinity advection feedback; (b) oceanic temperature advection feedback; (c) feedback associated with the THC reversal in the uncoupled OGCM; and (d) feedback associated with the southward shift of the ITCZ in the AOGCM.

(the salinity difference between the Atlantic and Pacific is $1.1 \mathrm{psu})$. Although the bottom circulation also presents different features in the two models, we found it contributes little to the different simulations of the salinity change because of the quite uniform distribution of salinity in the deep ocean.

[32] Seidov and Haupt [2003, 2005] have shown that whether the THC can operate or not depends more critically on the Atlantic-Pacific salinity asymmetry than on the highlatitude freshwater forcing in the North Atlantic. Although the THC is switched off by the high-latitude freshwater perturbation, this switch-off is temporary in the AOGCM because the fundamental condition for the THC operation, the pronounced higher-than-normal salinity in the Atlantic, still exists, whereas it disappears in the uncoupled OGCM. Consequently, once the high-latitude freshwater perturbation is removed, the high basin-averaged salinity in the Atlantic turns on the THC again in the AOGCM. In summary, the reversal of the THC in the uncoupled OGCM contributes significantly to the decrease of the mean salinity in the Atlantic and is therefore identified as a strong positive feedback to stabilize the "off" mode of the THC in the uncoupled OGCM (Figure 10c). Although this feedback may appear to be similar to the oceanic salinity advection feedback (Figure 10a), it is not. The latter links the THC and the salinity in the high latitudes of the North Atlantic. In contrast, the feedback associated with the THC reversal links the THC and the basin-averaged salinity in the entire Atlantic. A similar role of the reversed circulation in stabilizing the "off" mode of the THC has also been found by Gregory et al. [2003] in an OGCM coupled to an atmospheric energy-moisture balance model. Saenko et al. [2003] pointed out that the THC reversal is a necessary condition for the "off" mode of the THC to be stable.

[33] To analyze further the behavior of the THC in the OGCM and AOGCM simulations, a temperature-salinity $(T-S)$ diagram of the SST and SSS responses over the perturbation region has been plotted (Figure 12). For the ocean-only model, the SST and SSS response roughly linearly to the perturbation freshwater fluxes less than $0.1 \mathrm{~Sv}$. However, a $0.2 \mathrm{~Sv}$ flux reduces the SSS to a very low value close to $30 \mathrm{psu}$, indicating a rapid transition has been triggered in the model. Because of the usage of different thermal boundary conditions the two versions of the uncoupled OGCM give quite different SST simulations: One is constrained to the climatological SST, and the other is free to change. Considering the similar hysteresis loops obtained by both versions of the uncoupled OGCM (Figures 9a and 9b), SSS is therefore the dominating factor in the THC dynamics. Unlike the ocean-only model, the coupled AOGCM always simulates a roughly linear response of the SSS to the freshwater perturbations.

[34] In the uncoupled OGCM simulation, the salinity of the upper ocean in the perturbation region decreases in response to a large freshwater input, and the resulting decrease in salinity spreads over the entire North Atlantic (Figure 13a). The salinity of the upper ocean in the AOGCM simulation also decreases in response to the freshwater addition, but the resulting decrease in salinity is confined to the high-latitude region (Figure 13b). Over the low-latitude Atlantic, along the route of the upper THC branch, the salinity increases in the AOGCM. These different salinity anomalies result from the positive feedback associated with the THC reversal in the uncoupled OGCM (Figure 10c) and a negative feedback in the AOGCM (Figure 10d). The latter is related to the enhanced evaporation over the low-latitude Atlantic and a southward shift of the Atlantic intertropical convergence zone (ITCZ) when the THC slows down in response to the high-latitude perturbation.

[35] The enhanced evaporation is caused by the oceanic heat accumulation in low latitudes after the THC shutdown. This oceanic heat was originally transported by the THC to the high latitudes of the North Atlantic. The southward shift of the ITCZ results from a southward movement of the Hadley circulation in the AOGCM induced by the interhemispheric seesaw pattern of the SST anomaly, with a cooling over the high-latitude North Atlantic and a warming over the South Atlantic [Dong and Sutton, 2002].

[36] Figure 14 shows the changes of precipitation $(P)$, evaporation $(E)$, and precipitation minus evaporation $(P-E)$ 


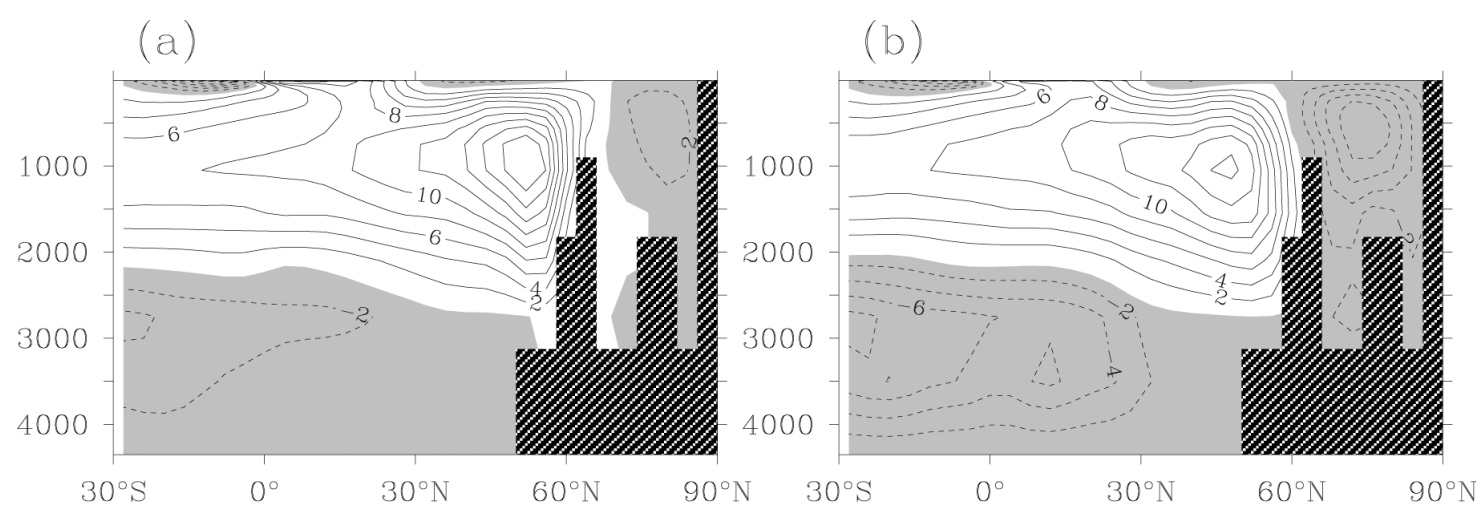

(c)

(d)

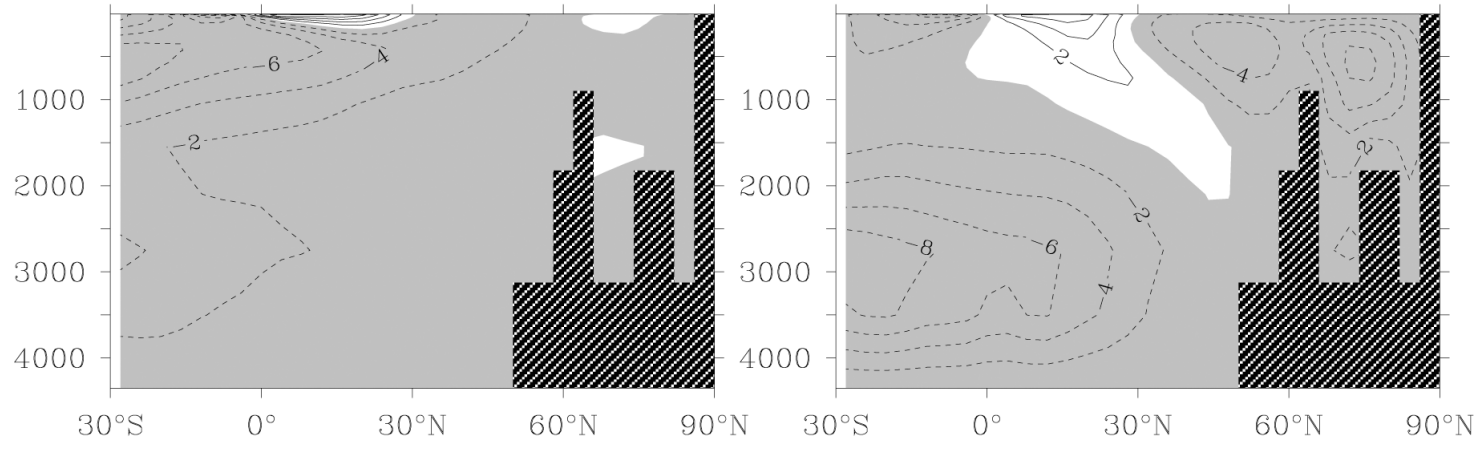

(e)

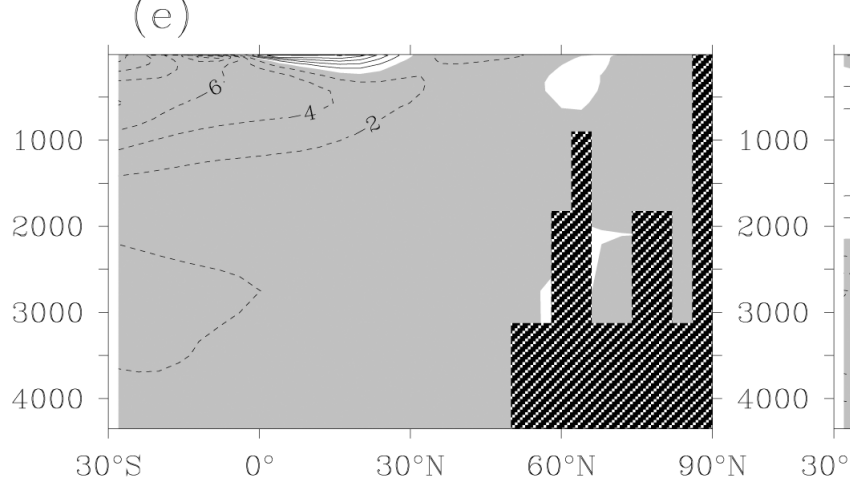

(f)

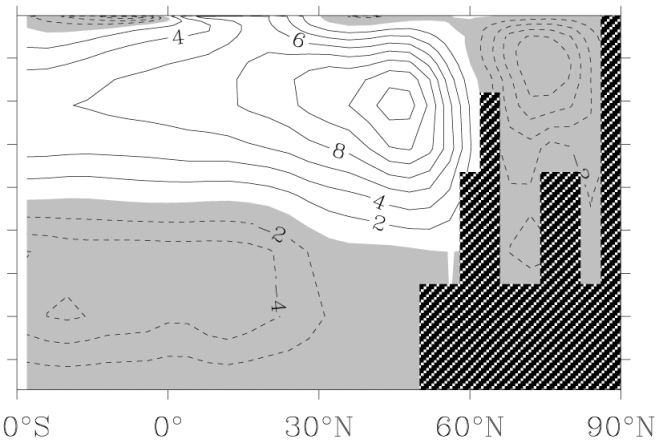

Figure 11. The evolution of the meridional mass stream function in the uncoupled OGCM (left) with mixed boundary conditions and (right) in the AOGCM. (a, b) Control runs (long-term mean); (c, d) $0.6 \mathrm{~Sv}$ hosing (the last 50-year mean in Figure 8); (e, f) dehosing (the last 30-year mean in Figure 8; the $0.6 \mathrm{~Sv}$ perturbation is removed). Units are $\mathrm{Sv}$.

after the shutdown of the THC in the AOGCM simulation. The dipole feature over the tropical Atlantic (Figure 14c) is clear evidence of the southward shift of the Atlantic ITCZ. The negative $P-E$ anomalies over the low latitudes of the North Atlantic enhance the SSS around the Caribbean Sea.

Table 2. Northward Salt Transport Across $30^{\circ} \mathrm{S}$ of the Atlantic Ocean in Upper $1000 \mathrm{~m}^{\mathrm{a}}$

\begin{tabular}{lcc}
\hline & Uncoupled OGCM & AOGCM \\
\hline THC "on" (control run) & 278 & 281 \\
THC "off" (0.6 Sv hosing) & -216 & 0.2 \\
\hline
\end{tabular}

${ }^{\mathrm{a}}$ Units are $10^{6} \mathrm{~kg} / \mathrm{s}$.
Consequently, seawater with higher salinity is transported northward by the gyre circulation and oceanic diffusion process from the low-latitude Atlantic. This transport partially compensates the initial salinity decrease induced by

Table 3. Basin-Averaged Salinity in the Upper $1000 \mathrm{~m}^{\mathrm{a}}$

\begin{tabular}{lccc}
\hline & Atlantic & Pacific & $\begin{array}{c}\text { Atlantic Minus } \\
\text { Pacific }\end{array}$ \\
\hline $\begin{array}{l}\text { Uncoupled OGCM } \\
\text { THC "on" }\end{array}$ & 33.8 & 32.9 & 0.9 \\
$\begin{array}{l}\text { Uncoupled OGCM } \\
\text { THC "off" }\end{array}$ & 33.0 & 32.9 & 0.1 \\
$\begin{array}{l}\text { AOGCM THC "on" } \\
\text { AOGCM THC "off" }\end{array}$ & 34.3 & 33.0 & 1.3 \\
\hline
\end{tabular}

${ }^{\mathrm{a}}$ Units are psu. 


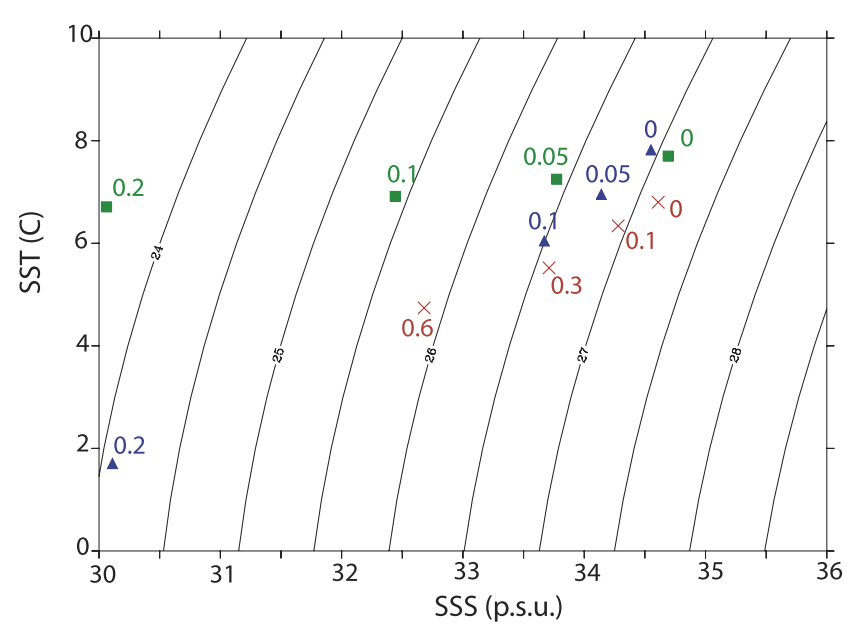

Figure 12. Temperature-salinity $(T-S)$ diagram showing the responses of SST and SSS over $50^{\circ}-70^{\circ} \mathrm{N}$ latitude of the North Atlantic to different freshwater perturbations. Values are 50-year means. Numbers beside the symbols indicate freshwater perturbations. (red crosses) AOGCM; (blue triangles) Uncoupled OGCM with prescribed fluxes; (green rectangles) Uncoupled OGCM with mixed boundary conditions. Contours are potential density $\sigma_{t}$ in $\mathrm{kg} / \mathrm{m}^{3}$. the freshwater perturbation. Thus the process associated with the southward shift of the Atlantic ITCZ operates as a negative feedback to destabilize the "off" mode of the THC (Figure 10d). The influence of the southward shift of the Atlantic ITCZ on the THC is similar to that of the extra freshwater export during the El Niño found by Schmittner et al. [2000].

[37] According to the zonally averaged salinity change in the Atlantic after the shutdown of the THC, a freshwater cap with salinity anomalies greater than 5 psu is formed at the upper North Atlantic in the uncoupled OGCM (Figure 15a). The freshwater cap spreads southward to the equator. The salinity anomalies become slightly positive south of the equator because of the shutdown of the THC. In contrast, the positive salinity anomalies in the upper Atlantic extend far northward to about $40^{\circ} \mathrm{N}$ in the AOGCM (Figure 15b). Because of the high basin-averaged salinity, oceanic deep convection and the North Atlantic Deep Water formation are more easily resumed in the AOGCM than in the OGCM after its cessation. Since the surface freshwater flux is prescribed in the OGCM for both types of atmospheric boundary conditions, the negative feedback associated with the southward shift of the Atlantic ITCZ cannot be simulated by the uncoupled OGCM.

\section{Discussion and Conclusion}

[38] This study focuses on the reversibility/irreversibility of the THC after its shutdown, simulated by two different models. Because the THC may slow down during this

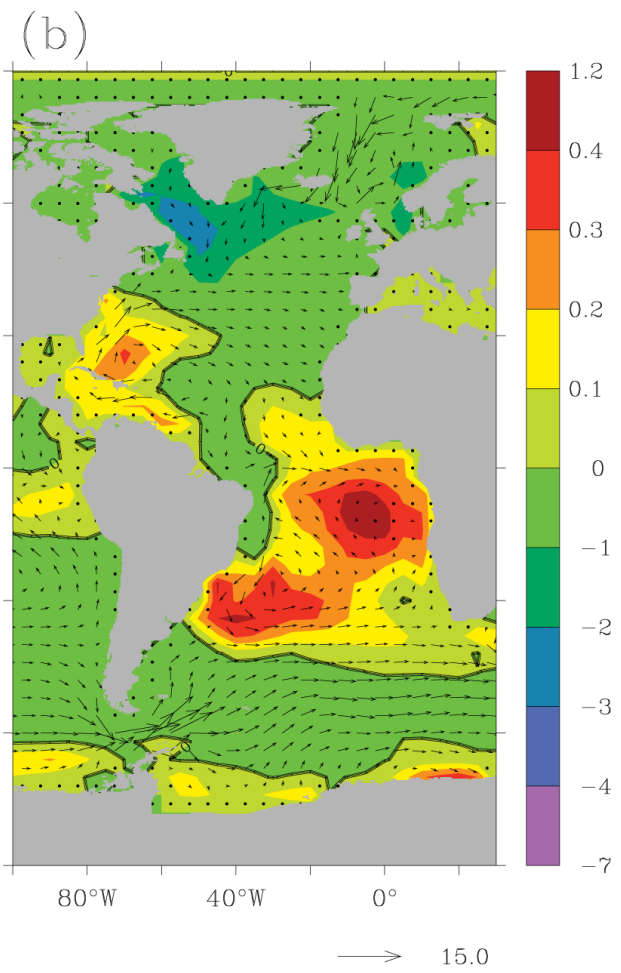

Figure 13. Change in salinity (parts per thousand) of the upper ocean $(100 \mathrm{~m})$ after the THC is shut down together with the upper ocean wind-driven circulation $(\mathrm{cm} / \mathrm{s})$. (a) $0.6 \mathrm{~Sv}$ freshwater perturbation in the OGCM with mixed boundary conditions. (b) $0.6 \mathrm{~Sv}$ freshwater perturbation in the AOGCM. All values are the mean of the last 50 years of simulations. 


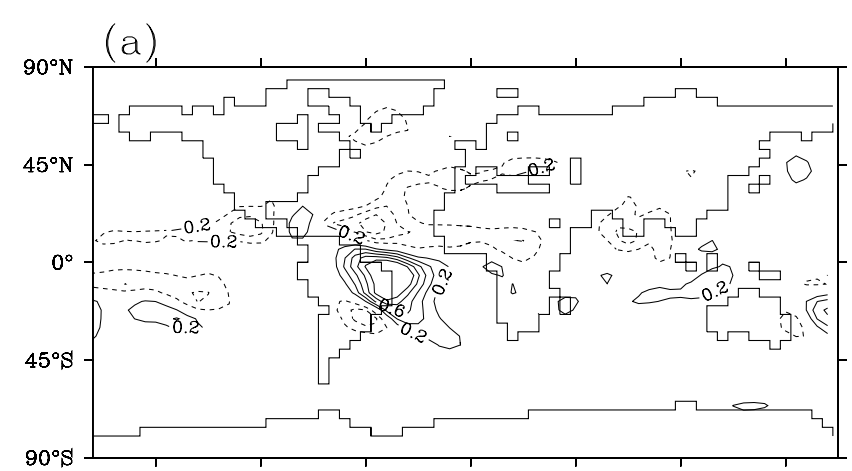

(b)
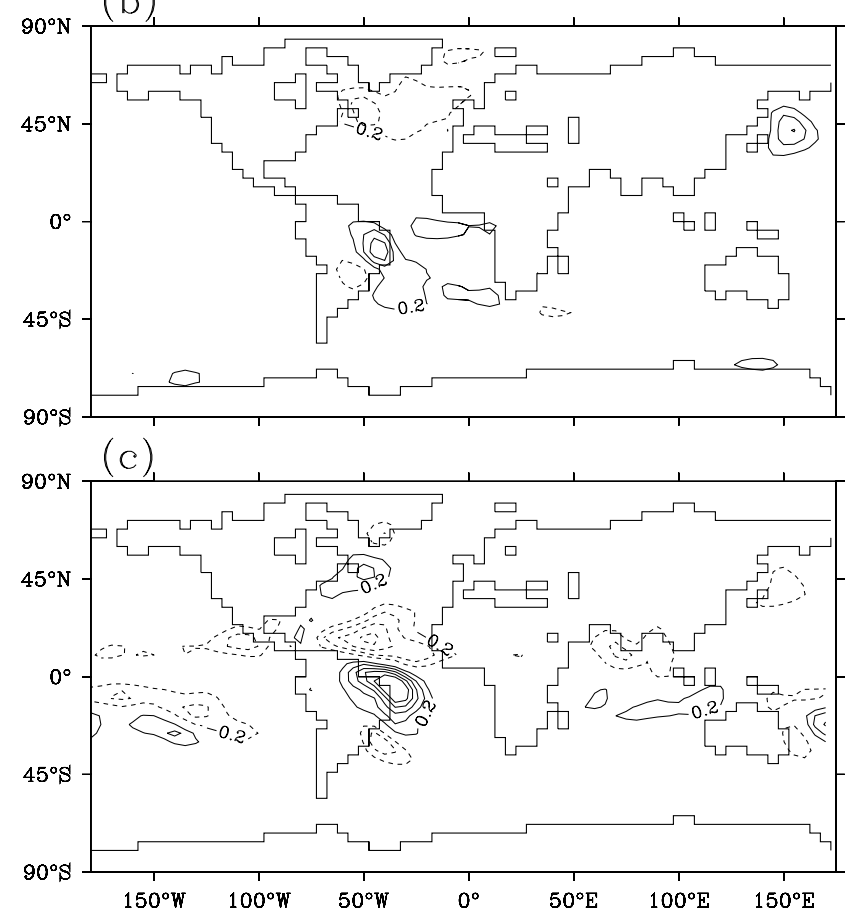

Figure 14. Changes of (a) precipitation $(P)$, (b) evaporation $(E)$, and (c) $P-E$ after the THC shutdown in the AOGCM simulation (50-year mean). Units are $\mathrm{mm} /$ day.

century, its dynamical behavior is a crucial issue. Simulations with the uncoupled UIUC OGCM and the fully coupled UIUC AOGCM have been carried out. The only significant difference between these models with respect to the THC simulation is the representation of the air-sea interaction. The results show that the shutdown of the THC is a reversible process in the fully coupled AOGCM simulation, while it is an irreversible process in the oceanonly model simulation.

[39] The different dynamical behavior of the THC in these model simulations results from the different feedback processes in the models. A positive feedback that cannot occur in the AOGCM has been identified in the uncoupled OGCM. This feedback is closely related to a reversed circulation in the upper Atlantic after the shutdown of the THC. Because of this reversed circulation the meridional salt transport at $30^{\circ} \mathrm{S}$ is also reversed in the uncoupled OGCM, and the entire upper Atlantic is dominated by a strong upwelling of less saline water from deeper ocean.
This THC reversal doesn't occur in the AOGCM simulation. Detailed salinity analysis indicates that although the freshwater perturbation in the high latitudes of the North Atlantic can slow down and even shut down the THC, the stability of the "off" mode of the THC is actually determined by the mean salinity in the Atlantic. The maintenance of a high basin-averaged salinity in the AOGCM simulation leads to a rapid recovery of the THC once the freshwater perturbation is removed, whereas the salinity decrease in the uncoupled OGCM has passed some critical point during the hosing period.

[40] A crucial negative feedback that cannot occur in the uncoupled OGCM helps the THC recover in the AOGCM. After the shutdown of the THC, the salinity of the upper ocean in the low-latitude North Atlantic increases as a result of an enhanced evaporation there and a southward shift of the Atlantic ITCZ, both of which are related to the SST change over the Atlantic. This change of SST, with cooling in the North Atlantic and warming in the South Atlantic, causes the annual mean maximum $P-E$ belt associated with the ITCZ to move from the North Atlantic into the South Atlantic. This facilitates the increase of the salinity in the upper ocean around the Caribbean Sea which is a critical region in regulating the intensity of the THC. Consequently, seawater with higher salinity is transported from the low latitudes to the high latitudes of the Atlantic by the gyre circulation and oceanic mixing process, partially compensating the freshening induced by the perturbation and therefore facilitating the resumption of deep convection after its cessation in the AOGCM simulation.

[41] The present study provides an interpretation of the different results obtained in the previous research on the THC. With the integration of the detailed and complex airsea interaction the UIUC AOGCM generated different feedback processes from the uncoupled OGCM, hence the behavior of the THC simulated by the ocean only model was modified. Of course the present results are based on a particular model system, and it has been demonstrated that there is uncertainty in simulating the THC and its dynamical behavior between model systems [Gregory et al., 2005; Stouffer et al., 2006]. Besides the air-sea coupling, other differences such as the representation of oceanic mixing, the use of a virtual salt flux over the ocean surface, and the hydrological sensitivity over the tropical Atlantic have impacts on the final solutions of models and therefore the bistability of the THC. In particular, the irreversible shutdown of the THC can occur in some models in which the air-sea interaction is represented [Saenko et al., 2003; Gregory et al., 2003; Stouffer et al., 2006]. Consequently, a robust determination of the causes of the difference in the THC dynamics should be the objective of a model intercomparison project (MIP).

[42] This notwithstanding, what lesson should be learned from the simulations by the UIUC OGCM and fully coupled UIUC AOGCM about the reversibility/irreversibility of the THC after its shutdown? It appears that the irreversible shutdown of the THC represented by the hysteresis loop of the OGCM simulations is a result of the domination of positive feedbacks associated with the oceanic salinity advection and the THC reversal in this model. The positive feedback resulting from the THC reversal cannot occur, and one negative feedback related to the latitudinal shift of the 

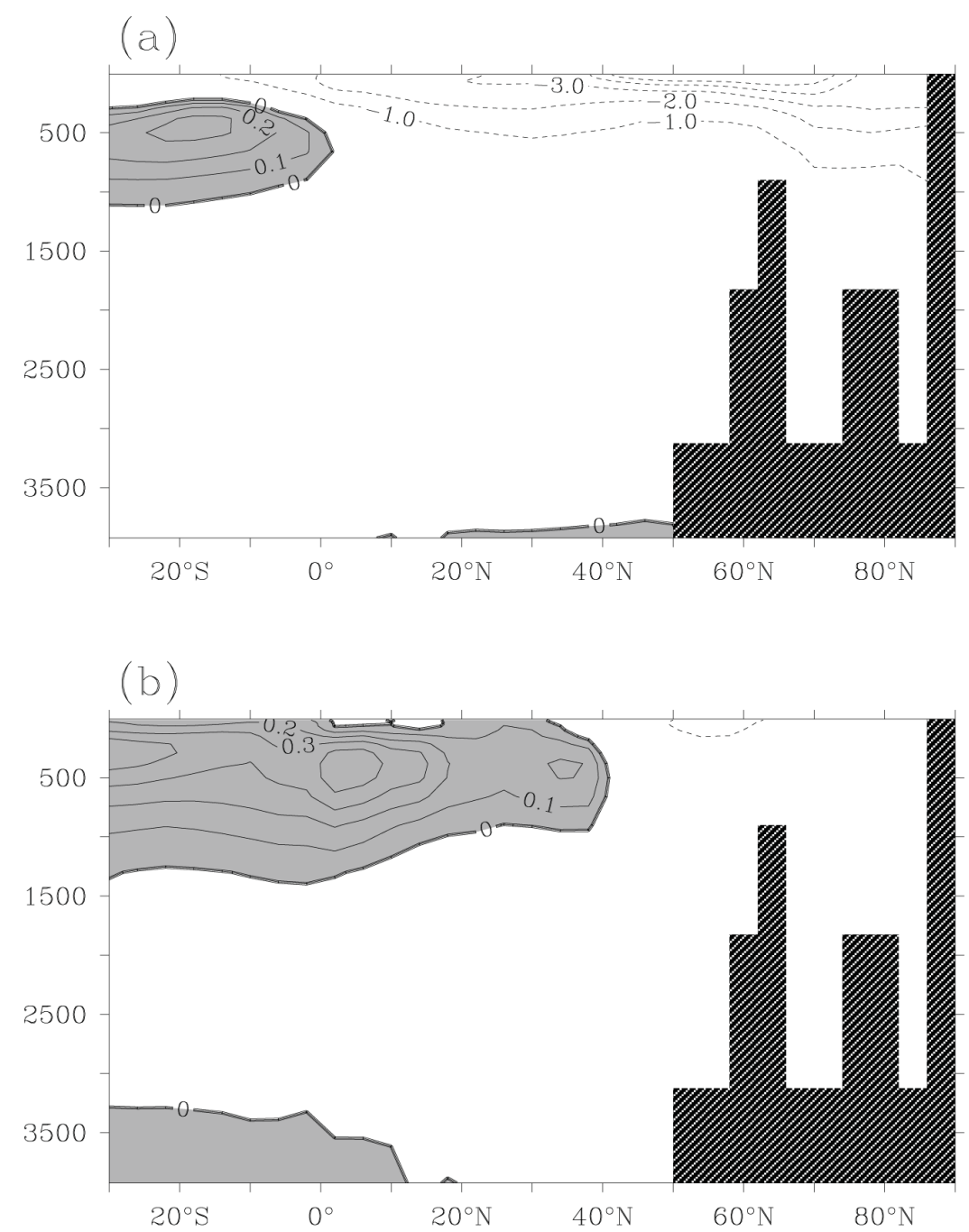

Figure 15. Zonally averaged salinity change in the Atlantic after the shutdown of the THC. (a) $0.6 \mathrm{~Sv}$ freshwater perturbation in the uncoupled OGCM with mixed boundary conditions; (b) $0.6 \mathrm{~Sv}$ freshwater perturbation in the AOGCM. All values are the 50-year mean. Units are psu.

Atlantic ITCZ can operate in the AOGCM. Given the large uncertainties in both models, the possibility of an irreversible shutdown of the THC cannot be completely excluded, hence policy options for such an occurrence should continue to be explored.

[43] Acknowledgments. We thank Jonathan Gregory, Atul Jain, Mankin Mak, Greg McFarquhar, Walter Robinson, and two anonymous reviewers for their constructive comments and discussions. This material is based upon work supported by the National Science Foundation under award ATM-0084270. Any opinions, findings, and conclusions or recommendations expressed in this publication are those of the authors and do not necessarily reflect the views of the National Science Foundation.

\section{References}

Arakawa, A. (1966), Computational design for long-term numerical integration of the equations of fluid motion: Two dimensional incompressible flow, part I, J. Comput. Phys., 1, 119-143.

Arakawa, A., and V. R. Lamb (1977), Computational design of the basic dynamical processes of the UCLA general circulation model, in Methods in Computational Physics, edited by J. Chang, pp. 173-265, Elsevier, New York.

Bryan, K. (1969), A numerical method for the study of the circulation of the world ocean, J. Comput. Phys., 4, 347-376.
Bryden, H., et al. (2005), Slowing of the Atlantic meridional overturning circulation at $25^{\circ} \mathrm{N}$, Nature, $438,655-657$.

Chou, M. D., and M. J. Suarez (1994), An efficient thermal infrared radiation parameterization for use in general circulation models, NASA Tech. Rep. Ser. TM-1994-104606, vol. 3, 85 pp.

Cubasch, U., et al. (2001), Projections of future climate change, in Climate Change 2001: The Scientific Basis. Contribution of Working Group I to the Third Assessment Report of the Intergovernmental Panel on Climate Change, edited by J. T. Houghton et al., Cambridge Univ. Press, New York. Curry, R., and C. Mauritzen (2005), Dilution of the northern North Atlantic Ocean in recent decades, Science, 308, 1772-1774.

Curry, R., B. Dickson, and I. Yashayaev (2003), A change in the freshwater balance of the Atlantic Ocean over the past four decades, Nature, 426, $826-829$.

Delworth, T., S. Manabe, and R. J. Stouffer (1993), Interdecadal oscillation of the thermohaline circulation in a coupled ocean-atmosphere model, J. Clim., 6, 1993-2011.

De Vries, P., and S. L. Weber (2005), The Atlantic freshwater budget as a diagnostic for the existence of a stable shut-down of the meridional overturning circulation, Geophys. Res. Lett., 32, L09606, doi:10.1029/ 2004GL021450.

Dong, B. W., and R. T. Sutton (2002), Adjustment of the coupled oceanatmosphere system to a sudden change in the thermohaline circulation, Geophys. Res. Lett., 29(15), 1728, doi:10.1029/2002GL015229.

Ganachaud, A., and C. Wunsch (2000), Improved estimates of global ocean circulation, heat transport and mixing from hydrographic data, Nature, $408,453-457$. 
Ganopolski, A., and S. Rahmstorf (2001), Rapid changes of glacial climate simulated in a coupled climate model, Nature, 409, 153-158.

Gregory, J. M., O. A. Saenko, and A. J. Weaver (2003), The role of the Atlantic freshwater balance in the hysteresis of the meridional overturning circulation, Clim. Dyn., 21, 707-717.

Gregory, J. M., et al. (2005), A model intercomparison of changes in the Atlantic thermohaline circulation in response to increasing atmospheric $\mathrm{CO}_{2}$ concentration, Geophys. Res. Lett., 32, L12703, doi:10.1029/ 2005GL023209.

Han, Y.-J. (1984a), A numerical world ocean general circulation model, part I: Basic design and barotropic experiment, Dyn. Atmos. Oceans, 8, $107-$ 140.

Han, Y.-J. (1984b), A numerical world ocean general circulation model, part II: A baroclinic experiment, Dyn. Atmos. Oceans, 8, 141-172.

Johnson, H. L., and D. P. Marshall (2002), A theory for the surface Atlantic response to thermohaline variability, J. Phys. Oceanogr., 32, 1121-1132.

Levitus, S., and T. P. Boyer (1994), World Ocean Atlas, U.S. Dep. of Commer., Washington, D. C.

Longworth, H., J. Marotzke, and T. F. Stocker (2005), Ocean gyres and abrupt change in the thermohaline circulation: A conceptual analysis, J. Clim., 18, 2043-2416.

Manabe, S., and R. J. Stouffer (1988), Two stable equilibria of a coupled ocean-atmosphere model, J. Clim., 1(9), 841-866.

Manabe, S., and R. J. Stouffer (1999), Are two modes of thermohaline circulation stable?, Tellus, Ser. A., 51, 400-411.

Marotzke, J., and J. Willebrand (1991), Multiple equilibria of the global thermohaline circulation, J. Phys. Oceanogr., 21, 1372-1385.

Mikolajewicz, U., and E. Maier-Reimer (1994), Mixed boundary conditions in ocean general circulation models and their influence on the stability of the model's conveyor belt, J. Geophys. Res., 99, 22,633-22,644.

Pacanowski, R. C., and S. G. Philander (1981), Parameterization of vertical mixing in numerical models of tropical ocean, J. Phys. Oceanogr., 11, $1443-1451$

Prange, M., V. Romanova, and G. Lohmann (2002), Influence of vertical mixing on the thermohaline hysteresis: Analyses of an OGCM, J. Phys. Oceanogr., 33, 1707-1721.

Rahmstorf, S. (1995), Bifurcations of the Atlantic thermohaline circulation in response to changes in the hydrological cycle, Nature, 378, 145-149.

Rahmstorf, S., and J. Willebrand (1995), The role of the temperature feedback in stabilizing the thermohaline circulation, J. Clim., 25, 787-805.

Rind, D., et al. (2001), Effects of glacial meltwater in the GISS coupled atmosphere-ocean model, J. Geophys. Res., 106, 27,335-27,353.

Saenko, O. A., A. J. Weaver, and J. M. Gregory (2003), On the link between the two modes of the ocean thermohaline circulation and the formation of global-scale water masses, J Clim., 16, 2797-2801.

Schiller, A., U. Mikolajewicz, and R. Voss (1997), The stability of the North Atlantic thermohaline circulation in a coupled ocean-atmosphere general circulation model, Clim. Dyn., 13, 325-347.

Schlesinger, M. E., et al. (1985), The role of the ocean in $\mathrm{CO}_{2}$-induced climatic warming: Preliminary results from the OSU coupled atmosphereocean GCM, in Coupled Ocean-Atmosphere Models, edited by J. C. J. Nihoul, pp. 447-478, Elsevier, New York.

Schlesinger, M. E., et al. (1997), Progress report for the second year, NSF/ DOE grant ATM 95-22681, Natl. Sci. Found., Arlington, Va.
Schmidt, M. W., H. J. Spero, and D. W. Lea (2004), Links between salinity variation in the Caribbean and North Atlantic thermohaline circulation, Nature, 428, 160-163.

Schmittner, A., and A. J. Weaver (2001), Dependence of multiple climate states on ocean mixing parameters, Geophys. Res. Lett., 28, 1027-1030.

Schmittner, A., C. Appenzeller, and T. F. Stocker (2000), Enhanced Atlantic freshwater export during El Niño, Geophys. Res. Lett., 27, 1163-1166.

Schmittner, A., M. Yoshimori, and A. J. Weaver (2002), Instability of glacial climate in a model of ocean-atmosphere-cryosphere system, Science, 295, 1489-1493.

Seidov, D., and B. J. Haupt (2003), Freshwater teleconnection and ocean thermohaline circulation, Geophys. Res. Lett., 30(6), 1329, doi:10.1029/ 2002GL016564.

Seidov, D., and B. J. Haupt (2005), How to run a minimalist's global ocean conveyor, Geophys. Res. Lett., 32, L07610, doi:10.1029/2005GL022559.

Stocker, T., and D. Wright (1991), Rapid transitions of the ocean's deep circulation induced by changes in surface water flux, Nature, 351, 729732 .

Stommel, H. M. (1961), Thermohaline convection with two stable regimes of flow, Tellus, 13, 224-230.

Stouffer, R. J., et al. (2006), Investigating the causes of the response of the thermohaline circulation to past and future climate changes, J. Clim., 19, $1365-1387$

Titz, S., T. Kuhlbrodt, S. Rahmstorf, and U. Feudel (2002), On freshwaterdependent bifurcation in box model of the interhemispheric thermohaline circulation, Tellus, Ser. A, 54, 89-98.

Vellinga, M., and R. Wood (2002), Global climatic impacts of a collapse of the Atlantic thermohaline circulation, Clim. Change, 54, 251-267.

Vellinga, M., R. A. Wood, and J. M. Gregory (2002), Processes governing the recovery of a perturbed thermohaline circulation in HadCM3, J. Clim., $15,764-780$

Wang, W., and M. E. Schlesinger (1995) The dependence on convective parameterization of tropical intraseasonal oscillations: An assessment using the UIUC GCM, in Proceedings of the First International AMIP Scientific Conference, Monterey, California, USA, 15-19 May 1995, WMO WCRP-92, WMO/TD 732, pp. 125-130, World Clim. Res. Programme, Geneva.

Yang, F. (2000), Radiative forcing and climatic impact of the Mount Pinatubo volcanic eruption, Ph.D. dissertation, 218 pp., Univ. of Illinois, Urbana-Champaign, Urbana, Ill.

N. G. Andronova, Department of Atmospheric, Oceanic and Space Sciences, Space Research Building, University of Michigan, 2455 Hayward Street, Ann Arbor, MI 48109-2143, USA.

B. Li and M. E. Schlesinger, Climate Research Group, Department of Atmospheric Sciences, University of Illinois at Urbana-Champaign, $105 \mathrm{~S}$. Gregory Street, Urbana, IL 61801, USA.

S. Malyshev, Department of Ecology and Evolutionary Biology, Princeton University, Princeton, NJ 08544-1003, USA.

J. Yin, Program in Atmospheric and Oceanic Sciences, P.O. Box CN710, Sayre Hall, Princeton University, Princeton, NJ 08544-0710, USA. (jianjun.yin@noaa.gov) 